Foro Interno. Anuario de Teoría Política

ISSN: $1578-4576$

\title{
La identidad ampliada: Eric Voegelin y el conocimiento terapéutico de la ciencia política
}

\author{
Silvina Vázquez ${ }^{1}$
}

Recibido: 18 de marzo de 2016 / Aceptado: 8 de julio de 2016

Resumen. A contracorriente de su tiempo, Eric Voegelin replanteó la cuestión de la ciencia política en los estratos más hondos del Ser. Su idea de la política como una ciencia del orden, cuyo vector trascendental despliega una triple representación de la noción de verdad (psíquica, política y cósmica) apunta hacia una recuperación de la problemática metafísica para las ciencias humanas. Con la cuestión metafísica y la problemática de la verdad, Voegelin atisbó en toda su complejidad el desafío que supone la simbiosis con la omnipotencia como dato político de la existencia humana. La trayectoria civilizatoria de Israel y Grecia supondrán en este camino dos hitos de diferenciación de la consciencia y de la identidad occidental. Dos caminos políticos paralelos que ofrecen distintas concepciones de la razón, del hombre y del poder.

Palabras clave: Identidad; ciencia política; orden; representación; verdad; razón.

\section{[en] Broadened Identity: Eric Voegelin and Therapeutic Knowledge of Political Science}

\begin{abstract}
Against the tendency of his times, Eric Voegelin revisited the question of political science in the deepest reaches of the Being. His recovery in the social sciences of issues dealt with in metaphysics involved the idea of politics as a science of order, with a transcendental vector that offered a triple representation of the notion of truth (psychic, political and cosmic). In both metaphysics and the problem of truth, Voegelin discerned the complexity of the challenge of symbiosis with omnipotence as a political datum of human existence. The trajectories of the Jewish and Greek civilizations offered two key points of differentiation of Western conscience and identity, two parallel political paths that provided differing conceptions of reason, humanity and power.
\end{abstract}

Keywords: Identity; political science; order; representation; truth; reason.

Cómo citar: Silvina Vázquez, La identidad ampliada: Eric Voegelin y el conocimiento terapéutico de la ciencia política: Foro Interno. Anuario de Teoría Política, vol. 16 (2016), pp. 17-44.

Los más viejos de entre nosotros no tenemos aún treinta años, y por lo tanto hemos ya despilfarrado grandes tesoros de amor, de fuerza, de coraje y de dura voluntad, con precipitación, con delirio, sin cuenta, sin perder el

\footnotetext{
1 Universitat de Barcelona (España).

E-mail: silvinavazquezmartinez@gmail.com
} 
aliento, a manos llenas...¡Nuestro corazón no siente la más ligera fatiga! ¡Está nutrido de fuego, de valor y de velocidad! ¡Es que vosotros no os acordáis de haber vencido nunca!...jEs que nosotros no queremos escuchar!...¡En pie sobre la cima del mundo lanzamos una vez más el reto a las estrellas! .

Filippo Tomasso Marinetti

Y con el siglo diecisiete comienza el increíble spectaculum de la Modernidad...con el resultado, en nuestro tiempo, de haber unificado a la humanidad en un loquero global, ardiendo con una vitalidad estupenda ${ }^{3}$.

Eric Voegelin

\section{La restauración de las ciencias humanas y la metafísica}

Comenzaremos nuestro recorrido aludiendo a la distinción entre actividad mental, cognición y pensamiento. Por sí misma, esta diferenciación contiene otra, de plena envergadura teórica, entre ciencia y filosofía. Mucho se ha discutido en el amplio campo de las ciencias sociales y la teoría política sobre la pertinencia o posibilidad de otorgarle a la teoría y al pensamiento político un estatus de cientificidad ${ }^{4}$. Si bien es cierto que las universidades de buena parte del mundo hoy incluyen en su oferta académica el anuncio de algo denominado como Ciencia Política (a veces, Ciencias Políticas, como dando a entender que no solo hay una forma de ciencia ni de política), no resulta evidente que la formación recibida por los alumnos tras esos años de estudio culmine en el aprendizaje de la capacidad para orientar la comprensión de lo político $^{5}$. Y tampoco para pensar u orientar la comprensión significativa de la o las ciencias y su relación con los eventos específicamente humanos. No se trata solamente

2 Filippo Tomasso Marinetti, "Le Futurisme": Le Figaro (20-2-1909). Esta es la traducción de Ramón González de la Serna publicada en la revista Prometeo, n. ${ }^{\circ} 2$ en abril de 1909 . Una versión electrónica de la misma traducción puede encontrarse en: https://www.uclm.es/artesonoro/FtMARINETI/html/manifiesto.html (20-82015).

3 "And with the seventeenth century begins the incredible spectaculum of modernity... with the result, in our time, of having unified mankind into a global madhouse bursting with stupendous vitality." Eric Voegelin, "Immortality: Experience and Symbol", en Published Essays 1966-1985, The Collected Works of Eric Voegelin, vol. 12, ed. de Ellis Sandoz, Louisiana State University Press, Baton Rouge, 1990, p. 55.

4 Donatella della Porta y Michael Keating (eds.), "How many approaches in the social sciences? An epistemological introduction", en Approaches and Methodologies in the Social Sciences, Cambridge University Press, Cambridge, 2008, pp. 19-39. Ver Gary King, Robert O. Keohane y Sydney Verba, Designing Social Inquiry. Expanded edition, Princeton University Press, New Jersey, 1995, pp. 3-6.

5 Comprensión que se asemeja más al pensar que al explicar. Excede el objetivo de este apartado discutir a fondo la cuestión de la comprensión. No obstante, en tanto que actividad relacionada intensamente con el pensamiento y, en menor medida, con el conocer merece cierta atención. Coincidimos con Arendt cuando se acerca a ella distinguiéndola de "la correcta información y del conocimiento científico". Y también cuando la caracteriza como un "complicado proceso que nunca produce resultados inequívocos...[es] siempre diversa y mutable...por la que aceptamos la realidad”. Más dudas nos genera, en cambio, cuando liga la comprensión a la reconciliación con el mundo. La comprensión, afirma Arendt, es "una actividad sin fin...por la que aceptamos la realidad, nos reconciliamos con ella, es decir, tratamos de sentirnos en armonía con el mundo". Las cursivas son mías. Hannah Arendt, "Comprensión y política", en De la historia a la acción, trad. de Fina Birulés, Paidós I.C.E. U.A.B., Barcelona, 1999, p. 29. 
de la tecnificación de la disciplina ni de la adopción acrítica y sin garantía alguna del tan discutido trasvase de los métodos de las ciencias naturales a las sociales ${ }^{6}$. $\mathrm{Ni}$ tampoco, aunque intuyo que se entrelaza de forma patente, con el progresivo repliegue de las asignaturas en teoría política, historia y humanidades ${ }^{7}$. Creo que este problema tiene raíces más hondas y que al observar ciertos conceptos desde un punto de vista menos convencional que el que nos ofrecen las explicaciones al uso, se proyectan sobre escenarios similares tonalidades muy diferentes. Tan diferentes que parecerían transformarlos al punto de volverlos irreconocibles. Algo de todo esto sucede con los conceptos de identidad e identificación del self ${ }^{8}$, donde la facultad para pensar se pone en juego de forma especialmente arriesgada' ${ }^{9}$. No es lo mismo pensar un concepto - permitiendo que este ilumine porciones de nuestra vida y de nuestra historia, resonando con sus connotaciones y denotaciones - que fusionarse $o$ identificarse con él (tanto negativa, como positivamente) y a partir de allí remodelarlo o demolerlo. Pero ¿en qué sentido decimos que se puede pensar y teorizar sobre la identidad y los procesos de identificación de los ciudadanos y las comunidades? ¿No esconde esta pregunta otra que nos devuelve al punto del cual habíamos partido respecto a la distinción entre ciencia y filosofía? Y si la distinción entre ciencia y filosofía es útil, ¿hasta qué punto se sostiene en dos experiencias diferentes de la realidad? ¿No será acaso la experiencia - concepto que no pretendemos definir y del cual tampoco podemos prescindir - aquello que media entre una cosa y otra? Si esto fuese así, ¿qué tipo de experiencia puede ligar la ciencia con la filosofía? ¿Y será prudente ligarlas o convendrá mantenerlas separadas, ajenas la una de la otra? Este trazado de fronteras, reivindicaciones de soberanía o demanda de reunificación de los saberes - acciones que son en definitiva de carácter político, más que científico

6 Es ingente la cantidad y calidad de filósofos, teóricos políticos y epistemólogos que han cuestionado, y desde hace mucho, la adherencia a los métodos provenientes de las ciencias naturales a la investigación en ciencias sociales. Enumerarlos acabaría por ser extenuante y superficial. La contienda al interior de la ciencia política sobre este asunto, sin embargo, continúa abierta. Un ejemplo en Alfred Schütz, "Formación de conceptos y teorías en las ciencias sociales", artículo presentado en la $33^{\text {a }}$ Reunión Semestral de la Conferencia sobre Métodos en Filosofía de las Ciencias, Nueva York, 3 de mayo de 1953. Está también publicado en Science, Language and Human Rights, American Philosophical Association, Eastern Division, vol. I, Philadelphia, 1952, pp. 43-86. Voegelin, por su parte, le quitaba importancia a este debate argumentando que quizás no fuera este el aspecto más tóxico del "dogma positivista”. Más destructivo le parecía la utilización del método —entendido principalmente como coherencia interna lógica de sus postulados-como único criterio de validez de la teoría. Ello "resulta en la abolición de la relevancia teórica". Eric Voegelin, La nueva ciencia de la política. Una introducción, trad. de Joaquín Ibarburu, Katz editores, Buenos Aires, 2006, p. 21.

7 Ruth W. Grant, "Political Theory, Political Science and Politics": Political Theory, vol. 30, n. 4 (August 2002), pp. 577-595. Para un texto clásico del empirismo cientificista y su rechazo a los asuntos morales sobre la ciencia política, puede consultarse: David Easton, “The Decline of Modern Political Theory": The Journal of Politics, vol. 13, n. $^{\circ} 1$ (1951), pp. 36-58. En cierta medida, el texto de Easton — a pesar de constituir una acerada crítica al estudio de la historia de las ideas como fuente legítima del conocimiento político - parece haber asumido casi todos los presupuestos del historicismo.

8 Tomo prestado del psicoanálisis el concepto de self que, en forma sucinta, podría ser referido a "las formas en las que el individuo reacciona ante sí mismo, en las que se percibe, piensa y valora así mismo y cómo, mediante diversas acciones y actitudes, trata de estimularse o defenderse". El self ("sí mismo" en castellano, aunque yo prefiero evitar esta traducción por su resonancia fuertemente dialéctica) sería, por lo tanto, un concepto intermedio, distinto del "yo" y del "ello" freudianos, aunque integrador de ambos. El self relaciona el mundo interno del individuo (tanto en su fuerza consciente como inconsciente) con su experiencia interpersonal. Para una discusión detallada sobre esta definición, ver León y Rebeca Grinberg, Identidad y Cambio, Paidós, Barcelona y Buenos Aires, 1993, pp. 30ss.

9 De forma análoga, la creciente búsqueda de comprensión o de sentido puede denotar una ofuscada carencia del mismo. Arendt comentaba que "la paradoja de la situación moderna parece consistir en el hecho de que nuestra necesidad de trascender la comprensión preliminar y la aproximación estrictamente científica procede de la pérdida de nuestras herramientas de comprensión”. Arendt, “Comprensión y política”, p. 34. 
o filosófico- ¿no comportará acaso alguna relación con la propia identidad de quien las experimenta? ${ }^{10}$.

Decía Hans Jonas que tres lecturas de su juventud habían marcado a fuego su vocación por la filosofía. Primero, la de los profetas de Israel; lectura que curiosamente no le llegaba de primera mano (considerando el fondo judío y religioso de su infancia) sino a través de los textos críticos escolares, escritos en alemán y no en hebreo, de marcada influencia protestante ${ }^{11}$. Segundo, la lectura de la Fundamentación de la metafísica de las costumbres, de Immanuel Kant. Y, en tercer lugar, el descubrimiento de los textos de Martin Buber dedicados al estudio del jasidismo y la mística judía ${ }^{12}$. Comenta Jonas, en el prefacio a la tercera edición de su estudio sobre el gnosticismo, que a partir de esas tres "experiencias mentales que de forma extraña se fusionaron" en su interior, no solamente se dio cuenta que debía estudiar filosofía, sino que también se apercibió de que "la religión es un aspecto esencial" de lo humano y que ningún estudio filosófico es posible si no es de alguna forma complementado a través del estudio del fenómeno religioso ${ }^{13}$. Para los que hoy nos dedicamos al estudio de la teoría y la ciencia política, esta declaración del filósofo judío-alemán nos genera asombro y sorpresa, un cierto desconcierto que invita amablemente a la indagación. Entrenados como hemos sido entrenados en la academia secular de las ciencias sociales positivas a separar tajantemente la ciencia de la filosofía y esta a su vez de la experiencia y el estudio de lo religioso; cualquier dicho sobre la complementariedad e irreductibilidad en la tensión entre razón y revelación, nos deja, como mínimo, intrigados.

En verdad, Jonas no fue ni el único ni el primero de los filósofos del siglo veinte, que en la estela del coro de pensadores enjundiosamente críticos con la Modernidad, alumbraría un tipo de filosofía que, por estar fuera del canon o en los márgenes de lo habitual, nos resulta hoy rica y original. Como sucede en cierta forma con Leo Strauss, y con algunos de los aspectos más intuitivos de la obra de Hannah Arendt — de quien es muy difícil decir que esté en los márgenes de nada, pues pocos pensadores políticos son citados y comentados hoy como ella ${ }^{14}$ - el caso de Jonas,

10 Creo que estas preguntas, al margen de que pudieran parecer capciosas, importan en aras de poder distinguir y diferenciar, más que reunir o religar. Aquello que considero fundamental distinguir en este aspecto es la experiencia de la identidad respecto de cualquier ideología sobre ella.

11 Jonas se refiere a H. Gunkel, M. Haller, H. Schmidt, W. Stark und P. Volz, Die Schriften des Alten Testaments in Auswahl neu iibersetzt und fur die Gegenwart erkldrt, Gottingen, 1911. Hans Jonas, The Gnostic Religion. The message of the alien God and the Beginnings of Christianity, Beacon Press, Boston, $3^{\mathrm{a}}$ ed., 2001, p. XXVII.

12 Martin Buber, Drei Reden uber das Judentum, Franffurt am Main, 1920; Die Legende des Baalscbem, Frankfurt am Main, 1922, ibídem. No hay traducción al castellano de esto textos. Del Segundo, sí la hay, en cambio, en inglés; Martin Buber, The legend of the Baal Schem, Princeton University Press, Princeton New Jersey, 1995. A modo de referencia puede consultarse en castellano: Martin Buber, Cuentos Jasídicos, Paidós, Buenos Aires, 1978, passim. Para una síntesis del pensamiento de Buber, ver Jacob Taubes, "Martin Buber y sus filosofía de la Historia" en Del culto a la cultura. Elementos para una crítica de la razón histórica, Katz Editores, Buenos Aires, 2007, pp. 52-69.

13 Jonas, The Gnostic Religion, p. XIV.

14 Sería más discutible, sin embargo, si la cantidad de citaciones se corresponde con la interpretación profunda y desprejuiciada de su labor teórica. A pocos teóricos políticos le es indiferente su obra, lo mismo ocurre con los acontecimientos de su vida. A día de hoy existen tanto biografías como películas y documentales sobre Arendt. A pesar de este éxito aparente y aun habiendo sido leída y comentada por filósofos e historiadores de gran renombre, Arendt fue el blanco de críticas de todo tipo. Algunas de ellas especialmente insidiosas con las contradicciones y repliegues de sus textos. Isaiah Berlin, llegó a decir: "Debo admitir que no respeto demasiado las ideas de la dama...todo es una corriente de asociación metafísica libre. Se mueve de una frase a otra sin nexos lógicos, sin vínculos racionales e imaginativos". Citado por Víctor Alonso Rocafort, "La libertad de movimiento en Hannah Arendt", en Retórica, democracia y crisis. Un estudio de teoría politica, Centro de Estudios Políticos y Constitucionales, Madrid, 2010, p. 250. 
como el de Eric Voegelin, nos abren una ventana para pensar desde los márgenes, o "sin barandillas"15 según la expresión de Arendt, sobre algunas de las omisiones y sucesivas desarticulaciones que se han ido manifestando, o que aún se encuentran latentes, en el pensamiento político desatado con la Modernidad. Específicamente para el caso de la teoría política que se interroga por el tema de la identidad, tanto comunitaria como individual, esto es doblemente importante. En primer lugar, porque con la Modernidad se delinean no solamente los contornos de una específica subjetividad, algo así como un tipo ideal de ciudadano ${ }^{16}$, el esbozo de un self. Y, en segundo, porque - de forma complementaria e inescindible - a partir de allí se resignifican también los límites y el contenido de las formas del conocimiento: no solo de este mismo self, en tanto que sujeto que puede conocerse a sí mismo, sino también del mundo que habita y del cosmos del cual emergen ambos. Esta relación entre self, mundo histórico o político y cosmos, mediada siempre por las concepciones metafísicas y epistemológicas de lo que debe ser la teoría, es lo afectado profundamente por la Modernidad misma, mucho antes de la era prodigiosa de los inventos técnicos y las revoluciones científicas del siglo diecisiete ${ }^{17}$.

Pero si volvemos a nuestros días, días de implacable especialización burocrática y determinación tecnológica ${ }^{18}$, ¿cómo, sino de forma inesperada e intrigante, podemos interpretar este párrafo de Voegelin en el que intenta sentar las bases de lo que, para él, es la ciencia política?

15 Hannah Arendt, "Discusión con amigos y colegas en Toronto" en Lo que quiero es comprender. Sobre mi vida y mi obra, Trotta, Madrid, 2010, p. 98. Ver también, Stan Spyros Draenos, “Thinking Without a Ground: Hannah Arendt and the Contemporary Situation of Understanding", en Melvin Hill (ed.), Hannah Arendt: The Recovery of the Public World, St. Martin Press, New York, 1979, pp. 209-223.

16 Tipo ideal que no evoca el modelo weberiano de análisis y clasificación de patrones heurísticos, sino más a bien un man written large en el que profundizo a continuación.

17 Estas relaciones transformadas entre cosmos, mundo histórico y self quedan muy bien retratadas en las frases finales del estudio de Alexandre Koyré, a propósito de la nueva cosmología y los sistemas de Laplace, resultantes de las teorías de Newton. Alexandre Koyré (1957), From the Closed World to the Infinite Universe, parágrafo 276. Disponible en: http://sacred-texts.com/astro/cwiu/cwiu15.htm (1-3-2016). No obstante, según Michael Allen Gillespie, la nueva cosmología y los "sistemas del mundo" descritos por Koyré parecen tener sus fundamentos epistemológicos bien abonados en la baja Edad Media; particularmente en la controversia que se da al interior del cristianismo entre la escolástica tomista y el nominalismo de pensadores como William de Ockham ( $c$. 1280/1288-1349). La tesis de Gillespie tiene cierta trascendencia, pues converge con la de Koyré (y hasta cierto punto con las del propio Voegelin) en tanto que sendos autores tienden a argumentar que con el transcurso de la Modernidad, antes que de la desaparición (o muerte) de Dios (o de la idea de omnipotencia), cabría más bien hablar de una transferencia de sus atributos, poderes o capacidades esenciales hacia otras dimensiones del ser, en concreto hacia la dimensión histórica y hacia la del self individual. En este sentido, la Modernidad, antes que borrar o hacer desaparecer a Dios, lo esconde y lo tapa. Ver Michael Allen Gillespie, The Theological Origins of Modernity, University of Chicago Press, London and Chicago, 2008, pp. 20-43. Por su parte, en el ámbito de la teoría política española, Javier Roiz observa cómo esta congestión entre los fundamentos del saber religioso y el científico cristalizan, ya entre los siglos doce y trece en la península ibérica, con motivo de la persecución religiosa y expulsión de las comunidades sefardíes. El hecho histórico de la persecución y posterior expulsión deja entrever una controversia teológica y política de primer orden entre la interpretación de la herencia griega que hace el cristianismo y la que elaboran y hacen confluir con el judaísmo los sabios y filósofos sefarditas. Como lo hiciera Leo Strauss (1899-1973), Roiz se detiene específicamente en la interpretación de La Guía de los Perplejos, en la que aparece delineada toda una concepción política del hombre y de sus relaciones con otros hombres en comunidad, así como también de su relación con Dios. Ver Javier Roiz, Sociedad vigilante y mundo judio en la concepción del estado, Editorial Complutense, Madrid, 2008, passim; Leo Strauss, "How to Begin to Study The Guide of the Perplexed", en Moses Maimonides, The Guide of the Perplexed, vol. I, The University of Chicago Press, Chicago, pp. XI-LVI.

18 Ver Sheldon Wolin, "La era de la organización y la sublimación de la actividad política", en Politica y Perspectiva. Continuidad y cambio en el pensamiento politico occidental, Amorrortu editores, Buenos Aires, 2001, pp. 377-382. 
El marco de referencia de la ciencia política ha cambiado considerablemente en los más de dos mil años desde su fundación. La ampliación de los horizontes temporales y espaciales ha cedido ante el análisis de enormes cantidades de materiales desconocidos en la Antigüedad. Y la aparición del Cristianismo en la historia, con la tensión resultante entre razón y revelación, ha afectado profundamente las dificultades del filosofar. El paradigma platónico-aristotélico de la mejor polis no puede dar respuesta a las grandes preguntas de nuestro tiempo... pero la situación básica de la ciencia política...no ha cambiado para nada. Hoy, como hace dos mil años, la episteme politiké trata sobre cuestiones que conciernen a todo el mundo y sobre las que todo el mundo se interroga...su método es todavía el del análisis científico. Y el prerrequisito del análisis es todavía la percepción del orden del ser en su origen transcendente, en particular la apertura amorosa del alma hacia la base transcendente del orden ${ }^{19}$.

Si bien no pocos investigadores y especialistas del área acordarían con Voegelin en que la episteme politiké se relaciona con temas y cuestiones que preocupan (o podrían preocupar) a todo el mundo. Igualmente, que su método o camino es el análisis científico de la realidad (aunque muchos de nuestros colegas cuestionarían ácidamente que la Grecia deAristóteles y Platón produjera conocimientos "científicos" de la política). Sin embargo, ronda la impresión que muy pocos de ellos estarían dispuestos a asumir, con Voegelin, que el prerrequisito para el análisis científico de la realidad política es la percepción del científico o del teórico político acerca de la búsqueda del orden del ser y la apertura amorosa del alma a su origen como parte de una realidad trascendente, es decir, una apertura hacia el orden atemporal de la política. La sola mención conjunta de los términos realidad y trascendencia (en donde el segundo término adjetiva al primero) levantaría ampollas, por no decir que incendiaría la observancia disciplinaria de los textos metodológicos ${ }^{20}$. En todo caso, no son las cualidades incendiarias ni las recalcitrantes de la teoría de Eric Voegelin

19 "The frame of reference of political science has changed considerably in the more than two thousand years since its founding. The broadening of temporal and spatial horizons has yielded to comparative analysis enormous amounts of material that were unknown in Antiquity. And the appearance of Christianity in history, with the resulting tension between reason and revelation, has profoundly affected the difficulties of philosophizing. The Platonic-Aristotelian paradigm of the best polis cannot provide an answer for the great questions of our time... But the basic situation of political science... has not changed at all. Today, just as two thousand years ago, politike episteme deals with questions that concern everyone and that everyone asks...its method is still scientific analysis. And the prerequisite of analysis is still the perception of the order of being unto its origin in transcendent being, in particular, the loving openness of the soul to its transcendent ground of order". Eric Voegelin, "Science, Politics and Gnosticism: Two Essays", en Modernity without Restraint. The Collected Works of Eric Voegelin, vol. 5, ed. de Manfred Henningsen, University of Missouri Press, Columbia, Missouri, 2000 , p. 259.

20 Wolin comenta que los metodólogos rara vez suelen asumir de entrada que la investigación en ciencias sociales pueda desarrollarse "paso a paso"; dicho esto, no obstante, la mayoría de ellos insiste en apuntar a un modelo que ata los razonamientos a modelos generales y estandarizados de proceder en la investigación y que se enumeran de uno en uno y siempre el línea ascendente, en donde el paso siguiente engloba al anterior. Mantener un orden cronológico de tareas, definir de forma compacta primero para posteriormente "operativizar" los conceptos principales con los cuales el investigador trabaja, garantizar la coherencia lógica interna de los enunciados, etc. Huelga decir que en este modelo cualquier alusión a conceptos que estén por fuera del orden temporal y material de la existencia son imposibles de estudiar y por lo tanto carecen de interés. Lo mismo sucede con la problemática de los significados asociada a la definición de conceptos. Ver, por ejemplo, Claire Selltiz et al., Research Methods in Social Relations (rev. ed.), Holt Rinehart \& Winston, New York, 1963, pp. 8-9. Citado en Sheldon S. Wolin, "La teoría política como vocación": Foro Interno. Anuario de Teoría Política, vol. 11 (2011), p. 193. 
— que podría argüirse que las tiene ${ }^{21}$ — sino por el contrario, las terapéuticas y apaciguadoras las que aquí tomaremos como punto de partida de nuestro trabajo.

Comenzaremos por justificar, entonces, nuestro interés en el estudio de la identidad comunitaria a través de un autor cuya visión teórica tanto de la identidad del self como también de la labor del teórico político se aleja del marco inmanente del conocimiento científico. Dicha inmanencia es la que fija de forma subyacente, de una vez por todas y para siempre, la metonimia baconiana - hoy asumida como axioma epistemológico por las ciencias sociales - acerca de que el conocimiento es poder ${ }^{22}$. No se pretende con esto dar por tierra con casi cinco siglos de ciencia y filosofía empírica y moral protestante ${ }^{23}$, sino más bien abrir o, mejor dicho, reabrir una de las clausuras teóricas que el problema de la inmanencia, que se inició con el paso a la Modernidad, y que hoy se denomina reduccionismo, inaugura. En este aspecto, Voegelin puede ser una gran ayuda.

La noción de que ciencia y filosofía es ante todo amor al saber y no posesión de conocimientos podría decirse que impregna casi toda la extensa obra de Voegelin y que encuentra su raíz en la experiencia de la philia aristotélica al sophon. Esta experiencia de amoroso asombro y apertura entiende nuestro autor que podría tener quizás un fundamento más confiable que la propia ontología:

El análisis platónico-aristotélico opera, de hecho, bajo la asunción de que la verdad del orden del ser...es objetivamente comprobable...El análisis, por lo tanto, es científico y conduce hacia una ciencia del orden a través del hecho y en la medida en que está ontológicamente orientado...De todas formas, la sola asunción - que el orden del ser es accesible al conocimiento, que la ontología es posible- no es por ella misma suficiente para llevar a cabo el análisis, puesto que la asunción puede estar infundada...Por lo tanto, una visión concerniente al

21 Recalcitrantes en el sentido de obstinadas o más bien limitadas; no, desde luego, en el sentido de reaccionarias, que es como a veces se interpreta el adjetivo. Según Marie L. Baird, por ejemplo, hay elementos para sospechar que en la obra de Voegelin hay una cierta propensión a no poder salir de un marco estrictamente cristiano para la interpretación de determinadas cuestiones que atañen precisamente a símbolos judíos de extrema relevancia política como, por ejemplo, el del siervo sufriente que aparece en Isaías: 52:13-53:12. Ver Marie L. Baird, "Eric Voegelin's Vision of Personalism and Emmanuel Levinas's Ethics of Responsibility: Toward a Post-Holocaust Spiritual Theology?": The Journal of Religion, vol. 79, n. ${ }^{\circ} 3$ (July 1999), pp. 393-395. Roiz también alude a las limitaciones de Voegelin a la hora de comprender las implicaciones de la teoría de Freud (a pesar de aquello que rescata), justamente porque pondrían llegar a desmantelar algunas de sus convicciones morales. Según Roiz, Voegelin mantiene un acercamiento ambivalente a Freud, tomando de él "la parte crítica que le conviene, sin tener que asumir la hondura del diagnóstico freudiano, probablemente insoportable para un hombre tan clásico moralmente como parece ser Voegelin". Javier Roiz, "Eric Voegelin: Existencia e inmortalidad", en $L a$ recuperación del buen juicio. Teoría política en el siglo veinte, Editorial Foro Interno, Madrid, 2003, p. 112.

22 Francis Bacon, The Great Instauration (1620). Disponible en: http://www.constitution.org/bacon/instauration. htm (15-8-2015).

23 En este sentido resultan muy interesantes las conexiones que establece y estudian tanto Wolin como Arendt respecto a la influencia de la moral calvinista en la ciencia política norteamericana, supuestamente libre de cualquier contenido o juicio de valor. Wolin, en un texto muy crítico de los nuevos métodos que la "revolución conductista" de las ciencias sociales (y en especial, la política) adquirían al precio de sepultar el estudio de la filosofía y la historia en el currículo académico, llega a referirse a los nuevos científicos como metodistas de las ciencias sociales, en irónica alusión a los metodólogos y a la corriente protestante fundada por John Wesley en el siglo dieciocho. Sheldon S. Wolin, "Political Theory as a Vocation": American Political Science Review, vol. 63, n. ${ }^{\circ} 4$ (1969), p. 1073. Por su parte, Arendt llega a sostener, en su ensayo sobre los conceptos moderno y antiguo de historia, que "el puritanismo y el empirismo inglés son solo las dos caras de una misma moneda". Hannah Arendt, "El concepto de historia: antiguo y moderno", en Entre el pasado y el futuro. Ocho ejercicios para la reflexión política, trad. de Ana Poljak, Península, Barcelona, 2003, pp. 91-92. 
ser debe estar siempre presente...El acontecimiento decisivo en el establecimiento de la episteme politiké fue el reconocimiento específicamente filosófico de que los diferentes niveles del ser que son distinguibles en el mundo están coronados por una fuente transcendente del ser y su orden. Y esta visión estaba enraizada en el movimiento real del alma espiritual humana hacia el ser divino experimentado como trascendencia. En experiencias de amor por el origen transcendente del ser, en la philia hacia sophon (la sabiduría), en eros hacia agathon (el bien) y en kalon (la belleza), el hombre se convierte en filósofo ${ }^{24}$.

Esta confianza de Voegelin en la experiencia del movimiento del alma humana hacia un ordenamiento jerárquico y trascendente del ser, quizás hoy resulte chocante o incomprensible ${ }^{25}$, objetable, anacrónica y para una época que se esmera en desdibujar las connotaciones benignas del fenómeno político de la autoridad ${ }^{26}$, parece sonar algo regresiva. Sin embargo, con un poco de paciencia en la lectura y si somos capaces de ir más allá de su tirantez ${ }^{27}$, interpretando el sarcasmo que también

24 "Platonic-Aristotelian analysis does in fact operate on the assumption that truth about the order of being...is objectively ascertainable...Analysis, therefore, is scientific and leads to a science of order through the fact, and insofar as it is ontologically orientated...The assumption alone, however - that the order of being is accessible to knowledge, that ontology is possible - is still not enough to carry out an analysis; for the assumption might be unfounded. Therefore, an insight concerning being must always be present... The decisive event in the establishment of politike episteme was the specifically philosophical realization that the levels of being that are discernible within the world are surmounted by a transcendent source of being and its order. And this insight was itself rooted in the real movements of the human spiritual soul toward divine being experienced as transcendent. In experiences of love for the world-transcendent origin of being, in philia toward the sophon (the wise), in eros toward the agathon (the good) and the kalon (the beautiful) man become philosopher". Voegelin, "Science, Politics and Gnosticism: Two Essays", pp. 258-259..

25 Como describe con precisión Jonas, en el mundo postcopernicano, en donde cualquier teleología ha sido eyectada del sistema de causas naturales, la naturaleza, categoría en sí misma percibida como sin propósito, deja de proveer la fuente de sanciones a cualquier propósito (o despropósito) humano. "Un universo sin una jerarquía intrínseca del ser, como el universo copernicano, deja a los valores sin soporte ontológico y el self es arrojado sobre sí mismo en su búsqueda de valores y significado". ("A universe without an intrinsic hierarchy of being, as the Copernican universe is, leaves values ontologically unsupported, and the self is thrown back entirely upon itself in his quest for meaning and values"). Hans Jonas, "Epilogue: Gnosticism, Existentialism, and Nihilism", en The Gnostic Religion, p. 323.

26 Para Arendt la autoridad es un fenómeno que "se ha esfumado del mundo moderno". De esta pérdida, ella arguye, el científico político apenas llega a "recordar que en tiempos, ese concepto fue fundamental para la teoría política o que la mayoría estará de acuerdo en que una crisis de autoridad...cada vez más honda ha acompañado el desarrollo de nuestro mundo moderno”. Hannah Arendt, “¿Qué es la autoridad?”, en Entre el pasado y el futuro, p. 145.

27 Voegelin es un autor sin demasiados lectores e intérpretes declarados en el mundo de habla hispana. Jesús Fueyo aludió a una "conspiración del silencio" en torno a él y que lo que no se le perdonaba a Voegelin en los círculos "más técnicos" era que plantee la ciencia política "en los estratos más hondos del ser". Ver Jesús Fueyo Álvarez, "Eric Voegelin y su reconstrucción de la ciencia política": Revista de Estudios Políticos y Constitucionales, n. ${ }^{\circ}$ 79 (1955), p. 68. Sin duda, el hecho de que haya sido leído y comentado por algunos de los intelectuales del régimen no debe de haber ayudado para una mejor recepción de su obra. Más recientemente, en el contexto de la ciencia política española, a excepción del texto ya citado de Javier Roiz, se ha afianzado una lectura prematura y muy selectiva de algunos de sus trabajos en clave reaccionaria. Se lo etiqueta a veces como a un anti-moderno o un anti-ilustrado. También le han desmenuzado analíticamente para demostrar su "falta de comprensión" de la ciencia avalorativa de Max Weber y "la superficialidad" de su crítica al sociólogo alemán. Ver por ejemplo, Javier Franzé, "Verdad y política: la crítica de Eric Voegelin a Max Weber sobre la relación entre ciencia y política": Astrolabio: Revista Internacional de Filosofia, n. ${ }^{\circ} 3$ (2006), pp. 31-60. En el mejor de los casos se lo suele asimilar con Leo Strauss y con su reivindicación de la filosofía clásica y la tradición. Ver Fernando Vallespín Oña, "La vuelta a la tradición clásica: Leo Strauss, Eric Voegelin", en Historia de la teoría política, vol. 5, Alianza, Madrid, pp. 342-382. 
la acompaña como la pantalla de un profundo desengaño, vemos entonces que hay algo más que enfado y amargura en la protesta de Voegelin ${ }^{28}$.

\section{El orden como vector de la política y la representación de la verdad}

Uno de los aspectos más llamativos del fragmento anteriormente citado es la relación que establece entre el asombro teórico y el concepto apenas esbozado de experiencia. Experiencia del teórico o spoudaîos ${ }^{29}$ que para Voegelin no nace con la observación directa de una realidad externa filtrada sensorialmente, sino con una comprensión interior y profunda, entre meditativa e intuitiva pero no por ello menos racional: un insight $\mathrm{o}$ visión interior con fuentes muy diversas ${ }^{30}$. A dicha visión, el spoudaîos solo puede llegar mediante la philia hacia Sofía o sabiduría, o a través del amor erótico hacia el bien y hacia las cualidades de la belleza. A estas experiencias del teórico, que entrarían dentro del orden del amor y los estados de paz, Voegelin también agrega aquellas experiencias que conforman y "purifican" el carácter del spoudaîos, del hombre bueno, experiencias que no se ciñen solo al ejercicio de las virtudes éticas y dianoéticas - especialmente la dikê platónica - sino principalmente a través de la autoridad que confiere al teórico la experiencia de Thánatos, es decir: la experiencia catártica de la muerte, junto con las vías de ascenso místico y con la de descenso anamnésico hacia la dimensión no-consciente de la psique ${ }^{31}$.

Al amor a lo sophón... ahora pueden agregarse las variaciones del Eros platónico hacia lo kalón y lo agathón, así como la dikê platónica, la virtud de la correcta jerarquización y subordinación de las fuerzas del alma, en oposición a la

28 Roiz destaca que "el antimodernismo [de Voegelin] no es tanto regresivo, como una postura dolida ante circunstancias que conoció de cerca y que le marcaron para siempre. Experiencias que lo llevarían a profundizar en lo que él consideró "la enfermedad del hombre moderno", y a desconfiar de las posibilidades de una Modernidad futura que daba por superados los traumas del holocausto y las guerras mundiales". Javier Roiz, "La teoría política de Eric Voegelin": Revista de Estudios Políticos (Nueva Época), n. 107 (Enero-marzo, $2000)$, p. 45. Si se atiende al tono de sus palabras, se podría decir que Voegelin parece a veces un autor indignado o deprimido. Ver, especialmente, Voegelin, "Immortality: Experience and Symbol”, p. 55.

29 Para diferenciar la noción de teoría de la opinión, Voegelin apela a la figura del teórico basándose en el spoudaîos que menciona Aristóteles en su Ética nicomaquea. El spoudaîos, u hombre bueno, es aquel capaz de realizar al máximo las potencialidades de la naturaleza humana, "el hombre que en su más completo grado de desarrollo es capaz de bios theortikós". Eric Voegelin, "Representación y Verdad”, en La nueva ciencia de la política, p. 83.

30 Fuentes, como por ejemplo, el lenguaje mito-poético o la teología.

31 La visión teórica toca, desde luego, el problema de la consciencia. En Anamnesis, repasa algunos aspectos de su trabajo previo "Time and Existence" publicado con motivo de su viaje a América. Allí realizaba un análisis comparativo de los conceptos de percepción y consciencia del tiempo en Franz Brentano (1838-1917), Edmund Husserl (1859-1938), Charles Sanders Peirce (1839-1914), William James (1942-1910) y George Santayana (1863-1953). Entonces había casi rozado la conclusión que el análisis de la consciencia había llegado a una vía muerta, en gran parte porque — según él — la descripción de los conceptos de percepción y consciencia se había probado como la construcción especulativa de una experiencia que no podía ser captada a través de conceptos puramente descriptivos. En este texto posterior, Voegelin cargará con las sucesivas reducciones en el análisis de la consciencia y llega a referir a lo "insostenible" de un concepto que no puede dar cuenta de su incompatibilidad con los fenómenos del sueño, los contenidos oníricos y el subconsciente. En un momento intenso del texto, Voegelin incluso llega a poner en duda el concepto de Yo: "It seems to me that there is no I that would be the agent of the constitution [of the consciousness]. It is doubtful whether consciousness has the form of the I, or whether the I is not rather a phenomenon in the consciousness". Y agrega en referencia a Freud: "one does not have to accept the psychoanalytical investigations regarding the $I$ and the $I d$ in order to acknowledge that Freud has seen certain fundamental givens of psychic life generally quite well. I cannot even find the I on the occasion of certain acts of will'. Eric Voegelin, Anamnesis, trad. y ed. de Gerhart Niemeyer, University of Missouri Press, Columbia and London, 1978, pp. 19; 15-17. 
polypragmosýne sofista; y, por sobre todo, debe estar comprendida la experiencia de Thánatos, de la muerte, como experiencia catártica del alma que purifica la conducta al colocarla en la más prolongada de todas las perspectivas de largo alcance. Bajo el aspecto de la muerte, la vida del hombre filosófico se convierte para Platón en la práctica de morir; las almas de los filósofos son almas muertas - en el sentido del Gorgias - y cuando el filósofo habla como representante de la verdad, lo hace con la autoridad de la muerte sobre la miopía de la vida...habría que agregar, aún dentro del campo platónico, las experiencias en las cuales la dimensión interior del alma se da en altura y profundidad...La dimensión de la altura se analiza a través del ascenso místico, por la vía negativa...que es el tema del Banquete. Se indaga la dimensión en profundidad por medio del descenso en el inconsciente ${ }^{32}$.

Se entiende así por qué, para Voegelin, la experiencia del teórico es ante todo una experiencia de integración psíquica de las distintas realidades interiores y exteriores con las que - a través de un cultivo específico- el hombre bueno o spoudaîos es capaz de cosechar los frutos del bios theoretikós ${ }^{33}$. De capital importancia para nuestros fines es que, en esta visión de lo que la teoría es, no se establece un cierre a priori ni del ascenso a los cielos ni del descenso en las profundidades del alma ${ }^{34}$, como tampoco se da un portazo a la complejidad de sus interrelaciones con el mundo histórico y el cosmos. En realidad, para Voegelin, la comprensión específicamente política comienza justamente desde allí: con la interrelación ordenada de estas dimensiones. De ahí su esfuerzo por restaurar lo que él entiende como una ciencia del orden, en la que la política simboliza un tipo específico de representación de la verdad. Verdad y orden del ser, podrían ser términos colindantes, a veces superpuestos, en la teoría del pensador colonés ${ }^{35}$.

Dicho orden se articula, además, mediante dos principios que el científico de la política debería ser capaz de deslindar: 1) el microcósmico, respecto al contenido de verdad que las sociedades políticas representan en la historia y 2) el macroantropológico, por el cual la ciudad o la comunidad política, representa a los

32 Ibid., pp. 84-85.

33 Bios theoretikós que, por momentos, Voegelin parece entender demasiado por encima del bios politikós. La música de fondo parece otorgar al primero un estatuto de privilegio en torno al segundo, emborronando en parte la experiencia política ateniense a partir de la cual ambos bioi (junto con la vida de los placeres del cuerpo) eran los modos de vida libre, aquellas que se elegían en libertad y que se distinguían de todas las actividades realizadas por necesidad, esto es: las labores de la esfera doméstica y la de los trabajos. La distinción entre los distintos bioi no parece preocupar en demasía al colonés. En este aspecto, parece seguir la tradición paulina, y sobre todo la de Tommaso d'Aquino. Alonso Rocafort, haciéndose eco de la reflexión arendtiana sobre esta distinción sostiene que "autores tan influyentes como Agustín de Hipona y Tomasso d'Aquino....afectaron al lenguaje político clásico. Se comenzó así a considerar vita activa a todo aquello que supusiera inquietud, mientras se dejaba como única forma de vida realmente libre a la vita contemplativa, es decir, el bios theoretikós platónico". Alonso Rocafort, Retórica, democracia y crisis, p. 280.

34 Profundidades del alma o descenso en el inconsciente que mantiene un eco intenso con el Acheronta movebo de Virgilio, que Freud recoge en La interpretación de los sueños. El verso, que Virgilio pone en boca de la diosa Juno, quien invoca a los dioses del infierno para generar una nueva guerra entre los supervivientes troyanos y los latinos: "Flectere si nequeo superos, Acheronta movebo" [ $\mathrm{Si}$ no puedo conjugar a los dioses celestiales, moveré a los de los infernos]. Para una discusión sobre el sentido que para Freud toma esta invocación puede consultarse: Juan Dorado Romero, Fantasías de omnipotencia en la ciencia y la política, tesis doctoral inédita, Departamento de Ciencia Política y de la Administración II, Universidad Complutense de Madrid, noviembre de 2015, pp. 459-461.

35 Voegelin se sostiene enteramente en Platón y en Agustín en este aspecto. Cita el Fedro y la Civitas Dei, como para respaldarse en este asunto de inmensa complejidad. Voegelin, "Representación y Verdad", p. 82. 
hombres, como si esta fuese el hombre mismo, escrito en extenso ${ }^{36}$. Este y no otro es el ordenamiento transcendente de las comunidades políticas humanas, con el que Voegelin se aproxima a su concepto de verdad:

Todos conocemos la tan citada frase de Platón de que una polis es el hombre escrito en grandes caracteres. Podría decirse que esta fórmula es el credo de la nueva época. Sin embargo, por mucho que ese principio deba ser limitado por la introducción de otros, y aunque haya que hacer concesiones a la verdad cosmológica y a la verdad que, después de todo, contiene...Hay que introducir la cuña de ese principio en la idea de que la sociedad solo representa la verdad cósmica, hoy tanto como en la época de Platón. Una sociedad política existente deberá ser un kosmión ordenado, pero no al precio del hombre. Debe ser no sólo un microcosmos, sino también un macroánthropos ${ }^{37}$.

Y aquí no habría lugar para una interpretación en clave regresiva, que sí asoma en algún que otro fragmento de su $\mathrm{obra}^{38}$. Aunque en su foro interno lo sienta probablemente así, aquí, sin embargo, Voegelin no está afirmando que existe una única verdad cósmica de la que se desprende un único ordenamiento político ${ }^{39}$. Más bien, lo que viene a decir es que distintos ordenamientos políticos de la sociedad tienden a comprenderse a sí mismos como los representantes de una verdad de tipo cósmica en la tierra (de ahí el término kosmión) aunque esto pueda simbolizarse de muy diferentes maneras ${ }^{40}$. Simultáneamente, se constituye el principio

36 Y aquí habría que proteger a ultranza la condicionalidad del verbo. El principio de correspondencia entre el foro interno de los hombres y la ciudad no necesariamente quiere decir que la sintonía entre la interioridad humana y la polis sea total, aunque quizás para Platón sí lo fuese. Pretender escribir toda la ciudad con los caracteres de la mente plantea el problema de la libertad de movimiento, de las proyecciones como fenómeno espurio, de la pluralidad frágil y al mismo tiempo inerradicable de los asuntos humanos. Ver Alonso Rocafort, Retórica, Democracia y crisis, p. 253.

37 Voegelin, "Representación y Verdad", pp. 79-80.

38 Como cuando, en lo que parece ser un eco severo de la doctrina protestante de la predestinación, se resigna a que solo por gracia divina "se comprende o no se comprende". En "Science, Polítics and Gnosticism", Voegelin estudia, además de los casos de Georg W. F. Hegel (1770-1831) y Marx, algunos fragmentos del Zarathustra de Friedrich Nietzsche (1844-1900) y se detiene con ahínco en "El canto de la noche". Nietzsche es para Voegelin, "el más sensible de todos los gnósticos" y se nota que lo juzga con respeto y admiración. Sin embargo luego de citarlo admite que "nadie escuchará sin sentirse conmovido este lamento de un hombre ante quien la humildad ante Dios no fue dada. Más allá de la psicología del poder de la voluntad, nos confrontamos con el hecho inescrutable de que la gracia viene dada o negada". ("[No] one will hear this lament of a man to whom humility before God was not given without being moved. Beyond the psychology of the will of power, we are confronted with the inscrutable fact that grace is granted or denied"). Voegelin, "Science, Polítics, and Gnosticism", p. 266.

39 Cuando analiza el posible conflicto "de verdad” entre el teórico y la sociedad, se pregunta: “ ¿se trata de un lenguaje vacío o existe realmente algo como una representación de la verdad que puede hallarse en las sociedades políticas de la historia?". Y se apura en prevenir cualquier interpretación inmanente de su pregunta: "De ser éste el caso, el problema de la representación no se agotaría en la representación en sentido existencial. Sería necesario distinguir entre la representación de la sociedad mediante sus representantes articulados y una segunda relación en la que la sociedad...se convierte en representante de algo que está más allá de ella misma, de una realidad trascendente". Y agrega: esta relación puede encontrarse tan atrás como se remonte la historia registrada de las grandes sociedades políticas, más allá del nivel tribal. Todos los antiguos imperios, tanto en el Cercano Oriente como en el Lejano Oriente, se consideraban representantes de un orden trascendente, del orden del cosmos; y algunos de ellos llegaban a entender ese orden como una "verdad". Ya se recurra a las más tempranas fuentes del Shû King o a las inscripciones de Egipto, Babilonia, Asiria o Persia". Voegelin, "Representación y Verdad", p. 71.

40 Así, por ejemplo, se permite comparar el orden cosmológico bajo la construcción imperial de Kuyuk Khan y Mangu Khan con el ordenamiento político expandido de la Unión Soviética, bajo la justificación del orden cósmico reemplazado por la verdad del orden histórico inmanente simbolizado por la dialéctica marxista. "La autocomprensión de una sociedad como representante del orden cósmico se origina en el período de los 
macroantropológico, mediante el cual, cualquier cambio en el ordenamiento político es correspondido por un cambio de los tipos humanos que se dan en el plano social o comunitario ${ }^{41}$. Cualquier reducción, corte o desequilibrio en la relación que ordena estas tres dimensiones de la realidad: cósmica, histórica (o política) y psíquica, sencillamente fomentan la destrucción del concepto de verdad que Voegelin quiere proteger, puesto que:

El hecho de que las diferencias de orden social se perciban como diferencias de tipos humanos se debe al descubrimiento de un orden verdadero de la psiquis humana y al deseo de expresar el orden verdadero en el medio social del descubridor. Ahora bien...el descubrimiento es un acto de diferenciación en un medio de opinión compacto; y, si el descubrimiento se relaciona con la verdad de la existencia humana, deberá provocar una conmoción en las convicciones más fuertes...del medio. En cuanto el descubridor empieza a comunicar, a pedir aceptación, a persuadir, inevitablemente encontrará una resistencia que puede resultar fatal, como en el caso de Sócrates. Así como en los imperios cosmológicos se descubría que el enemigo era el representante de la Mentira, ahora, a través de la experiencia de la resistencia y el conflicto se descubre que el adversario es el representante de la no verdad, de la falsedad, del pseudos, en relación con el orden del alma...el tipo verdadero es el filósofo, mientras que el sofista se convierte en el arquetipo del desorden ${ }^{42}$.

El concepto de verdad que Voegelin rescata del mundo clásico, por lo tanto, tiene una cualidad terapéutica inestimable, pues mediante su efecto apaciguador mantiene en sintonía la proporción y estructura del gobierno de la mente con el de la comunidad política y este a su vez con el del orden atemporal del cosmos y de la existencia. En el proyecto científico que Voegelin restaura la teoría recobra su dignidad y el rango de nobleza — dado por Platón_ pues únicamente en modo contemplativo se

imperios cosmológicos, pero no se limita a ese período...[a pesar que la verdad del orden es simbolizada de forma inmanente] el movimiento comunista es un representante de esa verdad que se simboliza de manera distinta en la misma medida que un Khan mongol era el representante de la verdad contenida en la Orden de Dios. La consciencia de esta representación lleva a las mismas construcciones políticas y legales que en los otros ejemplos de representación imperial de la verdad". Ibid., pp. 76-77. Esta representación "imperial” o monádica de la verdad en la historia se rompe, para Voegelin, con distintos estallidos de la verdad filosófica y profética entre los siglos octavo y tercero a. C. que van desde: Lao-Tse y Confucio en China, hasta las escuelas filosóficas orientales; pasando desde los Upanishads en India, hasta Buda y el zoroastrimo en Persia, para llegar el Israel de los profetas y en Grecia con la invención de la tragedia y los filósofos griegos a partir de Heráclito. Ibid., p. 78.

41 Se refiere a los diferentes tipos de gobiernos citados Platón en República, VIII-IX; cómo estos se corresponden con un tipo humano en concreto y de qué manera los cambios de gobierno representan un cambio en el tipo de alma de los hombres que gobiernan. Allí, Sócrates le pregunta a Glaucón: "Y sabes...que es forzoso que existan también tantas especies de caracteres humanos como formas de gobierno? ¿O crees que los gobiernos nacen de alguna encina o de alguna piedra y no de los caracteres que se dan en las ciudades...?’. Platón, República, trad. de Manuel Fernández-Galiano y José Manuel Pabón, Alianza, Madrid, 2006, 544-e.

42 Voegelin, "Representación y Verdad", p. 81. 
puede articular la experiencia de la búsqueda de sintonía entre la psique y el orden atemporal de la existencia ${ }^{43}$. Como recuerda Hans Jonas:

Los antiguos llamaron contemplación, theoria, a ver lo que está ahí, en la naturaleza, como es en sí misma, al Ser. Pero...si solo se contempla lo que queda como existencia irrelevante, entonces la teoría pierde el estatus de nobleza que una vez tuvo...La teoría tuvo esa dignidad por sus implicaciones platónicas porque vio objetos eternos en las formas de las cosas, una trascendencia del ser inmutable que brilla a través de la transparencia del devenir. El ser inmutable es eterno presente, en el que la contemplación participa por una breve duración del presente contenido en el tiempo ${ }^{44}$.

Ahora bien, el reconocimiento de que el bios theoretikós se mueve en la trayectoria de la trascendencia y de que la ciencia política no puede eludir el problema de la verdad $^{45}$, no ocluye que la ciencia sea al mismo tiempo un conocimiento de segundo orden, edificado sobre el conocimiento pre-científico de la realidad ${ }^{46}$. Esto último implica, de una forma u otra, tanto que el hombre no puede estudiarse solo a sí mismo - pues no controla la substancia interna que le provee de hechura-y que el mundo político y de sentido común que le precede informa todo el planteo teórico posterior, sin que tal planteo pueda salirse completamente de él. De ahí que nuestro pensador no se canse de repetir que la sociedad, al igual que el hombre, no es un "objeto" de estudio para la ciencia, como cualquier otro objeto del mundo exterior ${ }^{47}$. Asimismo, para Voegelin, el problema no solamente consiste en las radicales limitaciones del sensorium humano a la hora de analizar la realidad. La cuestión es aún más complicada puesto que de prestar atención humilde a este mundo interno del sujeto - sin mapas ni cartografías - lejos de arribar a certezas y leyes, más bien se llega a esa consciencia del "suelo sin fondo" trascendental (consciousness of the ground $)^{48}$ sobre el que el ser humano vive su existencia ${ }^{49}$. Un suelo que replantea a

43 "Si se adopta ahora la medida platónica podría decirse, por lo tanto, que el principio antropológico en una interpretación teórica de la sociedad exige el principio teológico como correlato. La validez de los criterios que desarrollaron Platón y Aristóteles depende de la idea de un hombre que puede ser la medida de la sociedad porque Dios es la medida de su alma". Ibid., pp. 89-90.

44. "To look at what is there, at nature as it is in itself, at Being, the ancients called by the name of contemplation, theoria. But...if contemplation is left with only the irrelevantly extant, then it loses the noble status it once had...Theoria had that dignity because of its Platonic implications - because it beheld eternal objects in the forms of things, a transcendence of immutable being shining through the transparency of becoming. Immutable being is everlasting present, in which contemplation can share in the brief durations of the temporal present". Jonas, "Epilogue: Gnosticism, Existentialism, and Nihilism", p. 338.

45 Fueyo Alvárez, "Eric Voegelin y su reconstrucción de la ciencia política", p. 92.

46 En referencia a la objeción epistemológica acerca de que las ciencias sociales (como la historia y la política) puedan constituir "un objeto" en el sentido que se entiende para las ciencias naturales, mantiene que "la objeción debe ser contrarrestada apoyándose en el principio epistemológico de que toda ciencia es un edificio construido sobre el conocimiento pre-científico del hombre". ("The objection must be countered back drawing on the principle of epistemology that all science is an edifice erected over the pre-scientific knowledge of man"). Voegelin, "What is History?", p. 8.

47 Ibidem. Voegelin, La nueva ciencia de la politica, p. 41.

48 Voegelin, "Immortality: Experience and Symbol", pp. 52-53, 77, 79. La traducción como consciencia del "suelo sin fondo" la tomo de Roiz, "La teoría política de Eric Voegelin", p. 67.

49 Roiz comenta que el término existencial, para Voegelin, incluye un aspecto no cognitivo del concepto de episteme "ya que episteme no es solo una función de la comprensión humana sino también una areté dianoética, es decir de una virtud que afecta hondamente al proceso del pensamiento". Roiz, "La teoría política de Eric 
la baja la autonomía del sujeto delante de su soledad inefable y que —además de la disolución de todo conocimiento filosófico y el retorno de la gnosis - involucra ingentes porciones de ansiedad ${ }^{50}$.

\section{Ansiedad de la razón}

Cuando la realidad se ha retirado del self, la cara se queda sin rostro ${ }^{51}$.

Eric Voegelin

Con vosotros están, con vosotros, ;oh afortunadísimos adolescentes!, todas las ciencias, si correctamente os conocéis a vosotros mismos ${ }^{52}$.

Giambattista Vico

El pensar el espíritu como raíz o anclaje, como la consciencia de un suelo sin fondo, presenta el desafío de hacerle espacio al misterio en la existencia del hombre. Es sabido que la ciencia moderna se lleva muy mal con este término; en el mejor de los casos acepta el de enigma que, a diferencia de lo misterioso, siempre tiene solución definitiva, como la de un rompecabezas o la de un código cifrado ${ }^{53}$. La consideración de aquello que no puede resolverse porque se funde con los principios del tiempo

\footnotetext{
Voegelin", p. 56. Es muy interesante la discusión que mantiene con Leo Strauss sobre el uso de este término, y que Strauss rechaza de plano por asociarlo al existencialismo moderno. Ver Carta de Leo Strauss a Eric Voegelin, 17 de diciembre de 1949 y la posterior con la respuesta de Voegelin, fechada el 2 de enero de 1950. Voegelin, Eric y Strauss, Leo, Fe y filosofia. Correspondencia 1934-1964, ed. y trad. de Antonio Lastra y Bernat Torres Morales, Trotta, Madrid, pp. 97-100.

so Soledad indecible que se ha planteado como relación del hombre con la totalidad, un término que Voegelin no emplea jamás y que, sin embargo, parece estar suspendido en sus textos, como flotando en el aire de sus preocupaciones. Según Josep Maria Esquirol, esta relación ha sido planteada por la filosofía a través de la metáfora del océano. Sin pretensión de equiparar el concepto de Voegelin de consciencia del suelo trascendental (o suelo sin fondo, como antes dijimos) al de océano, sí parece oportuno reunir a ambas experiencias por su condición de ambivalencia para el ser humano. En referencia a la totalidad del océano, dice Esquirol: "Más que sentirnos en el medio del mar, como una ola más que a él se une, nos sentimos en la roca, al lado del muelle, ante la inmensidad. Una inmensidad que, como dice Pascal, a veces nos calma y otras nos espanta". Cursivas en el original. Josep Maria Esquirol, La resistencia intima. Ensayo de una filosofia de la proximidad, Acantilado, Barcelona, 2015, p. 136.

51 "When reality has receded from the self, the face becomes faceless". Voegelin, "Immortality: Experience and Symbol", p. 62.

52 Vico, “Oración I" en Obras, p. 12. Citado por Alonso Rocafort, Retórica, democracia y crisis, p. 205.

53 La solución del enigma suele ser siempre una y definitiva, a diferencia de los misterios que pueden albergar varias respuestas, incluso contradictorias entre sí. Javier Roiz retoma la figura mitológica de la Esfinge, que aparece en el Edipo rey de Sófocles. La Esfinge era el demonio mitológico que custodiaba el camino hacia Fócida. Roiz, El mundo interno y la política, p. 39. Solía posar distintos acertijos y adivinanzas a los caminantes. Cuando Edipo acierta el enigma que ella le plantea, la Esfinge se suicida. Al replicar enfurecido a Tiresias, que le había prevenido de vivir sin saberlo en el más "vergonzoso comercio con el ser que te es más querido y que ignoras la abyección en la que vives", Edipo, en un arrebato de arrogancia negadora, le replica: “...vamos a ver, en fin, dime ¿cuándo te has mostrado adivino clarividente? ¿Por qué, cuándo la Esfinge proponía en este país unos versos enigmáticos no dijiste una palabra para liberar de ella a los ciudadanos?...En aquella ocasión no te mostraste ni inspirado por los dioses ni enterado por la ciencia augural. Y yo llegué entonces; yo, Edipo, el ignorante, y con la sola luz de mi espíritu y sin saber ciencia augural, conseguí reducir a la Esfinge a silencio". Sófocles, Edipo rey, Pehuén editores, Santiago de Chile, 2001, p. 12.
} 
y de la vida, con "la experiencia primaria del cosmos" ${ }^{54}$ y con la experiencia primaria de la psique, se volvió con la Ilustración ${ }^{55}$ o bien un problema de ámbito indiscutible o bien el imperio de la cancelación. Siguiendo a Voegelin, como he intentado explicar en el apartado anterior, ambas experiencias (la de la representación de la verdad del cosmos y la de la representación de la verdad de la psique) se encontrarían estrechamente vinculadas, independientemente de los estilos en que dicha representación se simbolice.

En las denominadas sociedades cosmológicas, la representación de la comunidad en la historia se desplegaba a partir de un entendimiento del orden principalmente dominado por la experiencia del origen cósmico. Este cosmos de la experiencia primaria, no tiene nada que ver con el cosmos de los objetos exteriores que el hombre encuentra cuando sale a explorar el mundo y, por lo tanto, ya se ha constituido como un self capaz de conocer la realidad que transita ${ }^{56}$. Se trataría, más bien de un cosmos compuesto por:

Una tierra por debajo y un cielo por encima, de cuerpos celestes y sus movimientos, de cambios estacionales, de los ritmos fértiles de la vida vegetal y animal; de la vida humana, del nacimiento y la muerte, y sobre todo...es un cosmos lleno de dioses $^{57}$.

El cosmos "lleno de dioses" al que Voegelin se refiere también es distinto del cosmos de Israel y el de la civilización cristiana. En el primero, la explicación sobre el origen se plantea en una sola dimensión de convivencia, allí se mezclan los dioses con los hombres, la materia en general con las representaciones ideográficas de la verdad ${ }^{58}$. En este sentido, las cosmológicas serían sociedades "compactas": ni el Egipto imperial de los faraones, ni las civilizaciones de la Mesopotamia ${ }^{59}$ habían extraído de la dimensión del cosmos las acumulaciones de poder propias de esos dioses cuyas acciones alcanzaban de pleno la vida material y la acción de los hombres ${ }^{60}$. Que los hombres, junto con la materia y la divinidad convivan en un mismo plano significa, en último término, que la omnipotencia es todavía un asunto que afecta profundamente lo humano. Algo que a Voegelin no se le escapa y que es

Voegelin, "Anxiety and Reason", p. 56

Ibid., pp. 80-81; Roiz, "La teoría política de Eric Voegelin”, pp. 40-41.

Ibid., p. 59.

"An earth below and a heaven above; of celestial bodies and their movements, of seasonal changes, of fertility rhythms in plant and animal life; of human life, birth, and death, and above all... it is a cosmos full of gods". Ibidem.

58 Roiz, "La teoría política de Eric Voegelin", p. 37.

59 El concepto de civilizaciones cosmológicas es mucho más amplio y roza sociedades muy distantes en el tiempo y el espacio, desde los imperios inca, maya y azteca hasta la China de la dinastía Zhou (Chou). Voegelin lo discute ampliamente en Israel and Revelation. El punto de partida de su estudio es la creación del mito cosmológico en dichas sociedades. De forma tentativa, Voegelin entiende que este es el momento de la primera creación simbólica a partir de la cual las comunidades humanas se elevan por encima de la organización tribal. Ver Eric Voegelin, Order and History: Israel and Revelation, vol. I, The Collected Works of Eric Voegelin, vol. 14, ed. de Maurice P. Hogan, University of Missouri Press, Columbia, London, 2001, pp. 50-53.

60 En este sentido cuando las acumulaciones de poder representadas por los dioses afectan la acción y conviven con los hombres, lo político adquiere significados muy diferentes. Mordazmente, Voegelin comenta que "aún durante los peores desastres políticos de los Períodos Intermedios en Egipto no apareció ningún profeta que proclamara un nuevo orden, ni tampoco se supo de movimientos revolucionarios que propusieran un orden alternativo al tipo tradicional del Imperio". ("Even during the worst political disasters of the Intermediate Periods in Egypt there arose no prophet to proclaim a new order, nor do we hear of revolutionary movements that proposed an alternative to the traditional type of empire"). Voegelin, "Anxiety and Reason", p. 61. 
el meollo del problema político, más que teológico, que él pretende tratar con su investigación histórica y filosófica ${ }^{61}$.

\section{Israel y la extrapolación de la omnipotencia}

Con Israel y con el surgimiento de la cultura helénica el planteamiento cosmológico se transforma. Allí se produce una importante diferenciación de la realidad en dos dimensiones que, hasta ese momento, se presentaba como compacta. El caso de Israel es paradigmático, pues marca la primera concentración de las fuerzas del politeísmo en un solo locus de poder, un único generador de orden en la existencia humana ${ }^{62}$. El primer paso es la concentración de las fuerzas divinas en un solo Dios ${ }^{63}$. El segundo, su extrapolación en un más allá al cual los hombres ya no podrán tener acceso: ni siquiera podrán representarlo con símbolos o imágenes. Para el judaísmo, Dios será vivido siempre como una ausencia y nunca como presencia activa en el mundo de los hombres ${ }^{64}$.

Con el Éxodo como salida hacia la libertad a través del desierto ${ }^{65}$ y con el establecimiento del pacto de Yahveh con Moisés, los israelitas junto con su líder

${ }^{61}$ Roiz entiende que Voegelin emplea el concepto de Dios como "un locus de poder, utilizado por el hombre para generar orden en su existencia". Roiz, "La teoría política de Eric Voegelin”, p. 37. También Athanasios Moulakis, editor del segundo volumen de Order and History, da cuenta de la cuestión política en Voegelin. Sin embargo, él decide atarla a la honda preocupación de Voegelin por la "corrosión del lenguaje" como una de las señas de las alteraciones modernas que impiden la comprensión de ciertas experiencias. Moulakis afirma que la habitual falta de nitidez para entender lo que Voegelin nos ha querido decir (aun reconociendo el uso de términos enrevesados y una prosa por momentos excesivamente recargada) es en sí mismo un problema de orden político. Athanasios Moulakis, "Editor's Introduction", en Eric Voegelin, Order and History: The World of the Polis, vol. II, The Collected Works of Eric Voegelin, vol. 15, ed. de Athanasios Moulakis, University of Missouri Press, Columbia, London, 2000 p. 2. Una interpretación plenamente teológica del primer volumen de Order and History, puede consultarse en Bernhard W. Anderson, "Politics and the Transcendent. Eric Voegelin's Philosophical and Theological Analysis of the Old Testament in the Context of the Ancient Near East": The Political Science Reviewer, n. ${ }^{\circ} 1$ (1971), pp. 1-29.

62 Roiz, "La teoría política de Eric Voegelin", pp. 37-38.

63 Voegelin, Israel and Revelation, pp. 408-409.

${ }_{64}$ "Somos pensamientos nihilistas en la mente de Dios", escribió Kafka. La temática de Dios como ausencia aparece evocada en su obra más bien de forma inquietante y angustiosa. Citado en Josa Fructuoso, "La escritura interminable: Edmond Jabès: un extranjero con un libro bajo el brazo”, en José Antonio Fernández López (ed.), Judaísmo finito, judaísmo infinito, ediciones Tres Fronteras, Murcia, 2009, p. 306. Pero el vacío del judaísmo no es solo angustia y desesperación. Rescatando un fragmento del pensamiento de Edmond Jabès (19121991) y la reflexión de M. Cacciari sobre aquel, Ricardo Forster sostiene que "el judaísmo contemporáneo (el que va de Rosenzweig, Kafka, Benjamin y Scholem hasta Jabès) constituye una resistencia de la palabra ante el avasallamiento de lo iconográfico. Estar a la escucha de un silencio, dejar que las palabras guíen los pasos del caminante que atraviesa el desierto constituye un tópico esencial del judaísmo; allí radica parte de la intransigencia hermenéutica, esa imposible negociación entre la palabra como jeroglífico del misterio de Dios, de su ausencia-presencia, y con una cultura de la imagen que atrapa el significado y completa el vacío dejado por Dios en su acto primigenio de creación". Cursivas en el original. Ricardo Forster, El exilio de la palabra. Ensayos en torno a lo judio, Libros ARCIS-LOM, Santiago de Chile, 1997, p. 30.

65 Voegelin remarca, como lo han hecho otros autores interesados por la experiencia judía, que la salida al desierto tiene un carácter sobre todo moral. No tiene que ver con la búsqueda de bienestar material, sino con la huida de la opresión y la corrupción del imperio bajo el faraón y la consiguiente renuncia a la omnipotencia. La cuestión material queda muy en segundo plano, y no vuelve a resurgir hasta la peregrinación, como se demostró durante el éxodo con las memorias nostálgicas de la vida culinaria de los judíos en Egipto. Voegelin, Israel and Revelation, p. 152. Como resalta Michael Walzer, la tiranía no solo es un régimen opresor, también puede ser un régimen atractivo. Y se fija en un pasaje del Éxodo, en donde se relata que al día cuarenta y cinco del peregrinaje por el desierto: "Toda la comunidad de los israelitas empezó a murmurar contra Moisés y Aaron en el desierto...Los israelitas les decían: ‘ Ojalá hubiéramos muerto a manos de Yahveh en la tierra del Egipto cuando nos sentábamos junto a las ollas de carne, cuando comíamos pan hasta hartarnos! Vosotros nos habéis 
pasan a ser el pueblo elegido ${ }^{66}$ de Dios. Salir al desierto, no solo significa liberarse de la opresión y la corrupción del Faraón, para Voegelin significa salir también del orden cosmológico en que hasta entonces se representaba la verdad:

El desierto es el símbolo de un impasse histórico. No fue un impasse específico, sino uno eterno en la existencia histórica en el "mundo"; es decir, en el cosmos en el que los imperios emergen y decaen sin más significado que un árbol que nace y muere, como si fueran olas en la corriente del eterno retorno. Por sintonía con el orden cósmico [de Egipto] lo fugitivos de la casa de la servidumbre no podían encontrar la vida que buscaban. Pero cuando el espíritu sopló, la sociedad en su forma cosmológica se convirtió en Sheol, la morada de los muertos. Pero cuando nosotros emprendemos el éxodo y vagamos por el mundo, para encontrar una sociedad nueva en otro sitio, descubrimos el mundo como si fuera el desierto ${ }^{67}$.

Los israelitas no luchan contra el Faraón, ni su huida al desierto precede la máxima que Benjamin Franklin (1706-1790), con toda la tradición del contrato moderno desde Locke, proponía como el gran sello de la revolución americana: "Resistir al tirano es obedecer a Dios"68. El Exodo judío es un escape hacia la libertad y no una resistencia activa. Comandados por Moisés, los israelitas se adentran en el desierto y esto no les evita caer en la desesperación y el desasosiego. Temer y murmurar, desistir y rebelarse a través de la falsa adoración serán comportamientos usuales allí donde la vida es precaria, fatigosa y, sobretodo, incierta.

La idolatría aparece por primera vez como un concepto en el orden de lo teológico y lo político ${ }^{69}$, para alumbrar las trampas o los obstáculos encontrados entre aquellos que habían renunciado a vivir en un cosmos "lleno de dioses" para reconocer como legítimo solo a uno. La falsa consolación —el desconsuelo del alma- a la que apunta la prohibición de idolatría describiría así el malestar de aquellos que

traído a este desierto para matar de hambre a toda esta asamblea"'. Exodo (16:2-3). Ver Michael Walzer, Exodus and Revolution, Basic Books, New Jersey, 1985, p. 33.

${ }_{66}$ Hay que enfatizar la gratuidad de la elección de Yahveh. Israel no resulta elegido (bahar), en virtud de sus cualidades especiales o porque se lo merezca por encima de otros pueblos, sino más bien porque ella reconoce a Yahveh como único Dios. "El Señor se prendó de ustedes y los eligió, no porque sean el más numeroso de todos los pueblos. Al contrario, tú eres el más insignificante de todos. Pero para cumplir el juramento que hizo a tus padres, el Señor los hizo salir de Egipto con mano poderosa, y los libró de la esclavitud y del poder del Faraón, rey de Egipto. Reconoce, entonces, que el Señor, tu Dios, es el verdadero Dios, el Dios Fiel, que a lo largo de mil generaciones mantiene su alianza y su fidelidad con aquellos que lo aman y observan sus mandamientos". Deuteronomio (7:7-9).

67 "Desert [is] the symbol of the historical impasse. It was not specific but the eternal impasse of historical existence in the 'world', that is, in the cosmos in which empires rise and fall with no more meaning than a tree growing and dying, as waves in the stream of eternal recurrence. By attunement with cosmic order [of Egypt] the fugitives from the house of bondage could not find the life they sought. When the spirit bloweth, society in cosmological form becomes Sheol, the realm of the death; but when we undertake the exodus and wander into the world, in order to find a new society elsewhere, we discover the world as the desert". Voegelin, Israel and Revelation, p. 153.

68 Walzer recalca que solamente Dios destruye los carros de Faraón, lo que permite escapar a los fugitivos de sus perseguidores. Y compara este hecho relatado en el Libro del Éxodo con la lectura de los patriotas americanos. La resistencia armada a la tiranía representaría más una cuestión de imitar a Dios, antes que de obedecerlo. Walzer, Exodus and Revolution, p. 32.

69 Ver Moshe Halbertal y Avishai Margalit, "Idolatry and Political Authority", en Idolatry, trad. de Naomi Goldblum, Harvard University Press, Cambridge, 1992, pp. 214-235; Daniel C. Harlow, "Idolatry and Alterity: Israel and the Nations in the Apocalypse of Abraham", en D.C. Harlow, M. Goff, K.M. Hogan, and J.S. Kaminsky (ed.), The "Other" in the Second Temple Judaism. Essays in Honor of John Collins, Eerdmans, Grand Rapid, 2011, pp. 302-330. 
no podrán imaginar a Yahveh más que como una ausencia. A partir de entonces tan solo contarán con la voz de los profetas y el abrigo de su comunidad como antídoto al desamparo. Sin embargo, también a la intemperie de la vida en el desierto le corresponde el espacio de la solitud donde se puede escuchar la voz del espíritu:

Cuando el mundo se vuelve desierto, el hombre está al fin en soledad, así puede escuchar la voz tronante del espíritu que con su susurro urgente le ha conducido y rescatado de Sheol. En el desierto Dios habló al líder y a sus tribus; en el desierto, escuchando la voz, aceptando su oferta y obedeciendo sus órdenes, al fin alcanzaron la vida y se transformaron en el pueblo elegido de $\operatorname{Dios}^{70}$.

Si bien se dice que Yahveh eligió a su pueblo cuando este aceptó obedecerle, también podría plantearse al revés: Israel acepta vivir en un mundo sin mezclarse con la omnipotencia y por esto puede reconocer, desde abajo y a mucha distancia, a su Dios, que quedará desde entonces desplazado en un más allá irrepresentable ${ }^{71}$. Y esto constituye un dato psíquico y político en tanto que plasma una noción muy distinta del poder. La extracción o retirada de Yahveh del mundo supone:

El acatamiento radical de esa resignación voluntaria a no seguir buscando la omnipotencia por ningún medio. No se puede nombrar, ni imaginar, porque entre ese locus de omnipotencia y el hombre no hay puentes que crucen el abismo; la brecha es esencial, no se puede cubrir jamás. No hay remedio a esta separación, ya que la omnipotencia no puede volver al cosmos ni lo humano acceder a la omnipotencia $^{72}$.

La experiencia espiritual del judaísmo fue la de la renuncia a la omnipotencia como fundamento psíquico de las relaciones entre los miembros de la comunidad. Políticamente, la experiencia adquirió forma como una monarquía bajo el amparo de Yahveh, con apertura a la función profética $^{73}$. Pero la renuncia voluntaria a la

70 "When the world has become desert, man is at last in the solitude in which he can hear the thundering voice of the spirit that with its urgent whispering has already driven and rescued him from Sheol. In the desert God spoke to the leader and his tribes; in the desert, by listening to the voice, by accepting his offer, and by submitting to its command, they at last reached life and became the people chosen by God". Voegelin, Israel and Revelation, p. 153.

71 Un más allá irrepresentable tan difícil de sostener en el día a día que Walzer apela a la autoridad de Maimónides (Moshe ben Maimon, 1135-1204) para matizar que "Dios reconoció el atractivo sensual de la idolatría egipcia para los israelitas y se acomodó a ello: la práctica del ritual sacrificial fue una concesión divina 'para que [al pueblo] se le dejara con las prácticas a las que estaban acostumbrados...y solo gradualmente fueran atraídos a la adoración pura de Dios". ("God recognized the sensual appeal of Egyptian idolatry to the Israelites and accommodated Himself to it: the practice of ritual sacrifice was a divine concession, 'so that [the people] should be left with the kind of practices to which they were accustomed...' and brought only gradually to the pure worship of God"). Walzer, Exodus and Revolution, p. 157, nota n. ${ }^{\circ} 34$. Walzer extrae de estos dichos de Maimónides así como de la experiencia de los judíos en el desierto una lección de gradualismo político. Ibid., p. 58.

72 Roiz, "La teoría política de Eric Voegelin", p. 38.

73 Para Voegelin, el Deuteronomio de la Torá es "una osificación del espíritu profético" que refleja la desesperación y las dificultades del movimiento profético para conciliar el establecimiento de un presente bajo Yahveh como único Dios de los hombres. Todo ello agravado por las condiciones existenciales de un pueblo cuya identidad pasaba de ser un cúmulo de vivencias simbolizadas por los clanes hebreos a transformarse mediante sucesivas amalgamas y asimilaciones con las sectas de Canaán, con las del reino davídico, incluyendo el de Judá, y posteriormente con la comunidad proveniente del exilio en Babilonia. Voegelin, Israel and Revelation, pp. 406407. 
omnipotencia no cierra del todo la puerta a la experiencia disolvente de la nada ${ }^{74}$. Paradójicamente, puede incluso intensificarla ${ }^{75}$. Con la desesperación de la nada sobreviene la necesidad de consuelo y con ella, el advenimiento de todos los mesías en la historia y el retroceso a lo cosmológico será siempre una posibilidad. El pueblo de Israel y los profetas entraron en la historia de la humanidad bajo un único Dios. Sin embargo, el retorno de la omnipotencia al mundo de los asuntos humanos y el propio fin de la historia, junto con el de la humanidad entera, será uno de sus desprendimientos.

\section{Grecia: mito, filosofía y sentimiento gentilicio de la polis}

Al igual que Platón, Voegelin afirma que mientras la experiencia de la trascendencia solo puede expresarse mediante "un movimiento del alma", es en la estructura existencial y temporal de la psiquis que los hombres pueden encontrar las huellas del marco que referencia el ordenamiento político de la comunidad. Al ser comprendida como un microcosmos la sociedad humana puede articularse como macroánthropos. Es decir: como man written large, como una comunidad política que cobra entidad en la medida que se proyectan sobre ella los diversos caracteres de la mente humana. Esto es lo que Voegelin denomina un salto en el ser (a leap in being) ${ }^{76}$ y es el evento esencial sobre el que pivota su personal filosofía de la historia. Lo dicho puede

74 Walzer señala que el episodio del vellocino de oro, es decir: el retorno a la adoración de viejos ídolos, marca la crisis política más profunda del Éxodo, la primera revuelta contra la autoridad de Yahveh y la posterior reprimenda a manos de Moisés, reinterpretada por el puritanismo inglés como la primera "purga" revolucionaria de la historia. Walzer, Exodus and Revolution, p. 59

75 Según la interpretación que Walzer hace del Éxodo, la huida de Egipto y el periodo de peregrinaje en el desierto estuvieron marcados por las murmuraciones y el miedo de los israelitas a enfrentarse y luchar directamente contra las fuerzas del faraón, en primer lugar, y respecto de la intemperancia de las condiciones de vida en el desierto y las dificultades para llegar a la tierra prometida sin la posibilidad de protegerse a través de los cultos e imágenes que había dejado atrás con la esclavitud, en segundo. Walzer es muy cuidadoso, sin embargo, de no sobredimensionar este aspecto del temor y de la falta de "heró́smo" del pueblo de Israel ni de caer en la imagen de un pueblo degrado por la opresión hasta el punto de lamentar su propia liberación. El motivo por el que Walzer intenta ponderar esta lectura parece ser el evitar llegar mediante ella a conclusiones más modernas, como la hegeliana, en las que, en virtud de la mentalidad y el comportamiento servil de los oprimidos, los líderes revolucionarios del pueblo podrían permitirse el mismo trato hacia ellos que el de los opresores. Walzer cita un revelador comentario de Hegel al respecto extraído de El espíritu del cristianismo: "Para los judíos una cosa estupenda se hizo...pero ellos no la inauguraron con acontecimientos heroicos propios...Los judíos vencieron, pero no lucharon... No hay que sorprenderse que esta nación, que en su emancipación trajera el más servil de los comportamientos, lamentara el haber escapado de Egipto". ("For the Jews a great thing was done...but they [did] not inaugurate it with heroic deeds of their own... The Jews vanquish, but they have no battled...It is no wonder that this nation, which in its emancipation bore the most slave like demeanor, regretted leaving Egypt"). Walzer, Exodus and Revolution, p. 48. La cita de Hegel está extraída de Georg W.F. Hegel, "The Spirit of Christianity", en On Christianity: Early Theological Writtings, Harper Torchbooks, New York, 1961, p. 190.

76 Salto (leap) o sintonización (attunenment) con el ser son expresiones muy reiteradas a lo largo de toda la obra de Voegelin y claves para comprender su noción de orden en la historia. Según Maurice Hogan, "Las sociedades desde sus inicios crearon una secuencia de órdenes que simbolizaban la verdad que pertenecía al orden del ser por el cual la sociedad se percibía como una parte...Para expresar este desarrollo en la historia, Voegelin usa términos como 'diferenciación', 'salto en el ser' y 'sintonía con el ser'. Sucesivos intentos de simbolización desde la base para una historia de la simbolización, que Voegelin caracteriza como un movimiento que va desde símbolos "compactos" a más diferenciados". ("Societies from the beginning have created a sequence of orders that symbolized the truth that pertains to the order of being of which society was seen to be a part... To express this development within history, Voegelin uses such terms as differentiation, leap in being, and attunement to being. Successive attempts at symbolization form the basis for a history of symbolization, which Voegelin characterizes as a movement from 'compact' to more 'differentiated' symbols"). Maurice Hogan, "Editor's Introduction”, en Voegelin, Order and History: Israel and Revelation, vol. I, p. 3. 
ocurrir en dos direcciones que son, es importante destacar, paralelas. La primera, como vimos en el caso de Israel, a través de la revelación de Yahveh a su pueblo (y del reconocimiento de este como su único Dios). La segunda, tiene que ver con el largo y complejo proceso por el cual la mentalidad helena, el alma griega, mutó desde su propia variante del mito cosmológico a lo que Athanasios Moulakis llama "la magistral evocación del efecto ordenador de la experiencia del orden en la forma de la filosofía platónica"'77.

La creación de la polis griega y la filosofía instaura para Voegelin una variedad especial de comportamiento humano que se encuentra a medio camino entre las sociedades cosmológicas y las históricas. Se trataría, al igual que en el caso de Israel, de un nuevo movimiento de diferenciación de la realidad compacta del ser a través de una transformación de la existencia y la forma de vida humana. No obstante, el caso de las poleis y la filosofía griega, lo es en un sentido bien distinto a la aportación hebrea.

Para el colonés, el descubrimiento de la psique corresponde a Homero y a Platón $^{78}$. Homero, el poeta ciego ${ }^{79}$, astutamente había percibido cierta concomitancia entre el desorden y la decadencia de la sociedad y el desorden o la corrupción del alma de sus miembros; especialmente entre aquellos de la clase gobernante ${ }^{80}$. Voegelin observa en esto un mérito considerable. Dado que la cultura helénica de entonces se sostenía en un tipo de simbolización aún rudimentaria - lo que implica la ausencia de una estructura conceptual adecuada - el apercibimiento de que el hombre alberga un alma, cuya propia organización interna se divide, al menos, en un centro de las pasiones y en un segundo centro que nuclea las capacidades del juicio y el conocimiento ${ }^{81}$, no es un evento menor. Homero, el aedo, observa sin ojos y le canta de oído a las experiencias del pathos y el logos — en este orden - cuatro siglos antes que Platón, aunque aún no puede nombrarlas como tales ${ }^{82}$.

77 Moulakis, "Editor's Introduction", p. 20.

78 Voegelin, The World of the Polis, p. 177. En Hesíodo, Voegelin aprecia una nota de este descubrimiento que, sin embargo, no llega a atravesar el nivel de la discusión crítica que puede alcanzar la lectura de Homero. Y comenta que la Teogonia y su titanomaquia, al fin y al cabo, no es más que el relato de la eliminación del orden los dioses más "impropios" hacia los más "decorosos” Zeus y Dikê. Ibid., p. 245.

79 Tradicionalmente se ha sugerido que el nombre del aedo contiene un juego de palabras con los vocablos ho me horón, literalmente 'el que no ve'. Roiz asocia sugestivamente, como lo hace el propio Homero, la pérdida de la vista con la profundización del oído y la voz. Roiz, El mundo interno y la política, p. 149. Sin quitarle poder

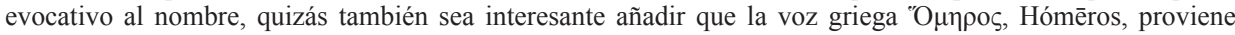
de la variante jónica Homaros, cuyo significado puede traducirse tanto como rehén o como huésped. Que ambos términos estén intensamente relacionados en la lengua griega nos habla de la estrecha conexión entre la experiencia de la hospitalidad y de la hostilidad hacia el extranjero. Ver Ángel L. Hoces de la Guardia y Bermejo, "La hospitalidad en Homero": Gerión: Revista de Historia Antigua, vol. 5 (1987), pp. 43-56.

80 Voegelin, The World of the Polis, p. 177.

81 Ibidem.

82 En un pasaje en donde reflexiona sobre las distintas actitudes de Aquiles y de Agamenon, Voegelin argumenta del siguiente modo: "Homero está encaminado hacia el descubrimiento de lo que los filósofos llaman el "verdadero self", esto es el área del alma humana por la cual se orienta hacia el orden noiético. Cuando el "verdadero self" domina, entonces el hombre "ve"; y gracias al reconocimiento retroactivo de la "ceguera" el error es integrado (como si fuese por una "consciencia") en el self actuante". ("For Homer is on the way toward discovering what the philosophers will call de 'true self', that is the area in a man's soul in which he is oriented toward noetic order. When the true self dominates, then the man 'sees'; and through the retroactive recognition of 'blindness', the misdeed is integrated [as it were by a 'conscience'] into the acting self'). Ibid., p. 174. 
El mito, el canto y, posteriormente, la tragedia ${ }^{83}$ aparecen así como los primeros lenguajes insertados en la matriz silenciosa del origen, la matriz del suelo sin fondo del que con cada diferenciación los hombres van tomando una nueva distancia. Todos estos lenguajes admiten a la vez una intuición imprescindible para la filosofía, aunque Platón descartaría la poesía y el teatro (los más retóricos) para admitir solo el lenguaje del mito ${ }^{84}$. Es recién con la Modernidad que esta relación de conocimiento interior y experiencia de lo trascendente se corroe por concurrencia de diferentes motivos $^{85}$.

Grecia representa para Voegelin el inicio de la filosofía y esto transforma en gran medida su investigación sobre la historia del orden. En palabras de Moulakis, a diferencia de la revelación de la ley mosaica, la filosofía helénica a partir de Platón:

Representa un alcance hacia arriba desde la psique humana hacia un agathon transcendente, un movimiento desde el polo humano de la "participación en el ser", más que un alcance hacia abajo desde el polo divino hasta el hombre ${ }^{86}$.

Según lo entiende Moulakis, el camino griego hacia "la participación en el ser" estaría planteado de abajo hacia arriba y no desde arriba hacia abajo, como el hebreo. La filosofía platónica construiría desde el suelo terrenal la línea de proyección hacia el cielo, hacia el bien transcendente, mientras que el Dios judío reconoce a su pueblo desde las alturas de la revelación a Moisés en el Sinaí. La interpretación corre más a cuenta de Moulakis que de Voegelin, creo. Puestos a comparar ambas experiencias, también dijimos que la experiencia hebrea podría plantearse exactamente al revés: porque Israel acepta una concentración de la omnipotencia en un solo locus de poder - y admite extrapolarla hacia un más allá irrepresentable, por fuera del cosmospuede reconocer a su propio y único Dios, precisamente desde abajo. La experiencia del reconocimiento del ordenamiento divino y su relación con el espíritu de la comunidad, puede plantearse de abajo hacia arriba o la inversa en ambos casos.

83 Lo que los poetas arcaicos habrían alcanzado era, "menos que la visión mosaica que emplazó al pueblo en el presente bajo Dios; pero fue más en la medida que los aedos apelaron a la psique de cada hombre cantando". ("Less than the Mosaic insight that placed the people in the present under God; but it was more, inasmuch as the singers appealed to the psyche of every man singly"). Ibid., p. 143.

84 Haciéndose eco de la obra de Cornelious Castoriadis, Dorado señala el origen de la tragedia como ritual religioso y su estrecho lazo con la democracia y la polis. Dorado Romero, Fantasías de omnipotencia en la ciencia y la política, p. 135. Con su habitual desprecio a los autores del teatro, Platón les advertía: "No creáis que...nosotros os dejaremos levantar alguna vez, tan fácilmente, escenarios en la plaza (el ágora) y presentar las actuaciones de actores de bella voz, que hablen más fuerte que nosotros, ni que os encargaremos dirigiros a los niños, a las mujeres y a todo el populacho, diciendo de las mismas costumbre e instituciones cosas que no son las mismas que las que decimos nosotros...”. Platón, Las leyes, trad. y notas de José Manuel Pabón y Manuel FernándezGaliano, Alianza, Madrid, 2002, 817 c-d, p. 388. Citado en Roiz, El mundo interno y la politica, p. 92.

85 En un comentario mordaz, uno de aquellos que alguien podría interpretar como anti-ilustrado o anti moderno, Voegelin compara a Homero con Hegel, en beneficio del primero, claro: "Homero pudo no haber inventado un símbolo altamente teórico como el mito de las nociones alternativas del universo en el Político de Platón. Y si recordamos que incluso un pensador moderno, con la experiencia de dos mil años de metafísica a su disposición, no pudo inventarse nada mejor que "la astucia de la Razón" para explicar el patrón de la historia, el logro de Homero al reconocer el problema guiará nuestro respeto". ("Homero could not yet invent a highly theorized symbol like the myth of the alternative notions of the universe in Plato's Statesman. And if we remember that even a modern thinker, with the experience of two thousand years of metaphysics at his disposition, could do no better than invent the List der Vernunft in order to explain the pattern of history, the achievement of Homer in recognizing the problem will command our respect"). Ibid., p. 178.

86 "Represents a reaching up from the human psyche toward a transcendent agathon, a movement from the human pole of the 'partnership in being', rather a reaching down from the divine pole toward man". Moulakis, "Editor's Introduction", p. 25. 
Las diferencias son otras y para nada menores. Para comenzar, allí donde la revelación a Moisés había llevado a la constitución de un pueblo bajo un solo Dios, la filosofía de Platón no conduce hacia la concreción de una sociedad específica. Las poleis griegas no son ni la creación ni la concreción de la filosofía platónica ${ }^{87} \mathrm{y}$ hasta cierto punto lo que emerge sería más bien cierta tensión entre ambas. Una tensión que a Voegelin no parece preocupar en demasía, en la misma medida que tampoco le preocupa reformular el concepto de lo político en sí mismo. No obstante, ya que concuerda con Aristóteles, Voegelin percibe al hombre de la polis como un paso más hacia esa diferenciación que permite extraer lo humano de su propio entorno, y por este motivo perfilarlo con mayor profundidad.

La política helénica se sale en parte de lo cosmológico en la medida que transforma al hombre en animal de polis, en politikón zôion. Nadie es para Aristóteles un animal político porque sea social o gregario, porque necesite de los otros para vivir, ni siquiera porque sea capaz de organizarse y constituir un gobierno, pues también lo forman las abejas y las hormigas ${ }^{88}$. La grandeza metafísica de la polis consiste, tanto para Aristóteles como para Voegelin, en transformar la vida del hombre por medio de la palabra, transportándolo así hacia el logos y la experiencia noética. Y todo ello a través de la urdiembre de un nuevo concepto de ley, nomos.

Distinto de physis o la esfera de lo natural, nomos procede del ámbito artificial de la política y eleva al hombre a un tipo de vida desconocido hasta entonces. Un tipo de vida que resitúa a los hombres mejor y los encamina en la trayectoria de la libertad. La polis genera leyes de todo tipo y de gran trascendencia, como consigna la expresión nomos basileus: "la ley es rey", que indica el propósito de no someterse más que a su propio imperio y de esta forma evitar la opresión entre hombres libres.

Ahora bien, Voegelin observa que la creación maravillosa de la polis no alcanza para salirse de lo cosmológico ${ }^{89}$. En esta perspectiva, el hombre queda todavía encerrado con la materia, con su cosmos originario y con el universo entero dentro del mismo ámbito de convivencia. La vida psíquica continua así mezclada con los dioses intracósmicos y los deseos ilimitados (es decir, soberanos) siguen rigiendo los pliegues de la vida política, como lo muestran las contiendas que canta Homero entre héroes, semi-dioses y deidades ${ }^{90}$. El "reto a las estrellas" desde "la cima del mundo" con el que abríamos este trabajo y que retornará violentamente en la voz de Marinetti a inicios del siglo veinte.

Por otra parte, de la misma manera que los asuntos humanos quedan recluidos en una misma dimensión de realidad, en un cosmos que aún sigue siendo "un cosmos lleno de dioses", el concepto de nomos no se escapa de cierto componente "parroquial", como destaca Voegelin ${ }^{91}$. Aun cuando nomos ejemplifica los avances de una cultura

87 Ibidem.

88 Aristóteles, Política, trad., prólogo y notas de Carlos García Gual y Aurelio Jiménez Pérez, Alianza, Madrid, 1993, 1253 a, p. 43.

89 Una interpretación posible, si bien no asumida explícitamente por Voegelin, indicaría que este no salirse de lo cosmológico en la cultura y la polis griega no solamente se relaciona con la permanencia de los dioses intracósmicos, sino también con la del apego territorial de los ciudadanos a las fratrías, las phylai y los gene o ancestros comunes, en suma, los lazos que él caracteriza como propiciadores del "sentimiento gentilicio". Voegelin, The World of the Polis, pp. 183-184.

90 Roiz, "La teoría política de Eric Voegelin", p. 38.

91 Voegelin, The World of the Polis, p. 181. 
que comenzaba a representarse a sí misma mediante la convención de la palabra y el pacto, el logro que esto supone queda recluido al interior de las murallas de la polis, excluyendo de su aplicación a todos aquellos otros que no pertenecían a lo que ya comenzaba a entenderse de forma organológica y que desde entonces ya anticipaba la metáfora escolástica del "cuerpo político" 92 . Hay que recordar una y otra vez el significado fuertemente territorial y de línea fronteriza que connota nomos, que en su acepción original quiere decir muralla: ley-muralla ${ }^{93}$. Nomos no solo es indiferente ante mujeres, niños y esclavos, como usualmente se argumenta, también lo es ante extranjeros y cualquier otra forma de vida que, por radicarse fuera de las fronteras de la polis, perdía su condición de humana ${ }^{94}$. A pesar de toda su grandeza metafísica ${ }^{95}$, la polis ateniense llevaba consigo cierta impronta tribal, por así decirlo, que, según Voegelin, fue lo suficientemente profunda como para marcar la estructura del orden histórico, tanto interior como exterior, de su existencia:

En tanto que ciudad...la polis nunca se desarrolló como una comunidad de ciudadanos individuales, unidos por el vínculo de una conjuratio al estilo de los pueblos medievales occidentales; en tanto que estado territorial, la polis nunca fue capaz de expandirse en una nación de ciudadanos individuales, como los estados nacionales occidentales. El individuo nunca obtuvo el estatus personal al interior de su unidad política que, bajo la influencia de la idea cristiana de hombre, caracterizó a la formación de la civilización occidental; siempre permaneció en un

92 La metáfora del cuerpo para dar orden y concierto a la comunidad política no es del todo transferible al mundo griego, aunque sí podría decirse que lo heredara. Voegelin recalca que el significado del término soma, que en griego moderno significa cuerpo, antiguamente se empleaba para designar solamente aquellos cuerpos muertos, los cadáveres; mientras que se reservaba el uso del término chros para connotar la forma visible del cuerpo humano. Ibid. p. 171.

93 Recientemente se viene discutiendo sobre la importancia mítica de la guerra de Troya, como guerra de exterminio y aniquilación del enemigo y su relación con la identidad griega. Dorado resalta el componente de miedo al descontrol y temor a la otredad que se encuentra impreso en el concepto de nomos, como origen de la cultura política griega. Ver Dorado Romero, Fantasías de omnipotencia en la ciencia y la política, pp. 80-82. Por su parte, Hannah Arendt aduce que si bien "originalmente la ley se identificó con esta línea fronteriza, que en los tiempos antiguos era...una especie de tierra de nadie entre lo público y lo privado...La ley de la polis superó este antiguo concepto, si bien conservó su antiguo significado espacial. La ley de la ciudad-estado no era el contenido de la acción política...ni un catálogo de prohibiciones... basado en el 'no matarás' del Decálogo. Literalmente era una muralla, sin la que podría haber habido un conjunto de casas, una ciudad (asty), pero no una comunidad política. Esta ley-muralla era sagrada, pero solo el recinto era político". Arendt, La condición humana, p. 81 .

94 Ibidem.

95 Arendt plantea la cuestión metafísica matizada mediante el espíritu agonal de los ciudadanos y la fundación de la polis como antídoto a la fragilidad de los asuntos humanos. Se entendía que la polis multiplicaba las posibilidades del individuo de ganar fama inmortal, es decir: de vencer las barreras del tiempo mediante la memoria de las generaciones futuras. La polis, complementaba de forma más sólida, por decirlo de alguna manera, la función de los poetas políticos como Homero, en el sentido que "parecía asegurar las más fútiles de las actividades humanas, la acción y el discurso". El factor transcendental no solamente asoma a través de hacer perdurar en el tiempo las acciones humanas y la palabra, tan cercanas a las historias heroicas, sino también en la deslocalización del espacio político, pues cada ciudadano lleva una polis en su interior: "a cualquier lado que vayas, serás una polis", cita Arendt. Frase que contiene la idea que la acción y la palabra entre aquellos que viven juntos son capaces de generar un propio y singular espacio entre los participantes que puede ser desarrollado más allá de todo tiempo y lugar. Ibid., pp. 224-225. 
status intermedio entre facciones tribales y los más estrechos lazos de sangre al interior de la polis ${ }^{96}$.

En el plano histórico, ni siquiera las reformas democráticas de Clístenes - que hicieron al requisito de ciudanía dependiente de la membrecía a los demoi y no a las phratriae y las phylai ${ }^{97}$ — permitió liberar la política del sentimiento gentilicio sobre el que se cimentaban sus primeras instituciones. En una declaración que, atendiendo de quien proviene difícilmente podríamos tildar de anacrónica o de estar sesgada por prejuicios modernos, Voegelin llega a admitir que a pesar de las reformas democráticas:

Solo el poder de los aristocráticos gene fue quebrado, no el espíritu gentilicio de sus instituciones. El demos, a pesar de su base territorial, era una corporación de personas, justo como las antiguas relaciones de sangre. Los atenienses obtenían su ciudadanía, no mediante un acto legal que hiciera a la persona miembro de la polis, sino a través de su pertenencia a un $\operatorname{demos}^{98}$.

Las phratriae o hermandades a las que Homero cantaba continuarán siendo el elemento clave con el que los ciudadanos quedan sujetos y unidos a su polis. La familia, la tierra, la sangre y el suelo señalan el límite de la experiencia trascendente de la política: "no hay cosa más dulce que la patria y los padres, aunque se habite en casa opulenta, pero lejana, en país extraño..."99. La nostalgia del suelo y las raíces familiares impregnan la cultura helénica de cierto atractivo sacrificial, pues más allá de su dulzura infantil, a ningún ciudadano "le será indigno, auxiliando a su patria, morir", advertía Héctor ${ }^{100}$. Pero los suelos con sangre, como descubrieron aqueos y troyanos en Ilión ${ }^{101}$, no necesariamente drenan hacia las raíces del suelo sin fondo

96 "As a city...the polis never developed into a community of individual citizens held together by the bond of a conjuratio like the Western medieval towns; and as a territorial state, the polis was never able to expand into a nation consisting of individual citizens like the Western national states. The individual never gained the personal status in his political unit which, under the influence of the Christian idea of man, characterized the formation of Western civilization; it always remained in a status of mediation through the factious tribal and narrower bloodrelationships within the polis". Voegelin, The World of the Polis, 183.

${ }_{97}$ Voegelin señala que las phylai o tribus al interior de la polis se distinguen etimológicamente de aquellas tribus asentadas por fuera o en otros territorios, conocidas como ethnos. Por lo que respecta a los lazos de sangre, diferencia desde la anchisteia, la unidad familiar que comprendía hasta tres generaciones y compartía tanto las leyes y rituales sagrados como los derechos de herencia, hasta los más grandes gene, las unidades familiares aristocráticas unidas bajo la descendencia de un ancestro común. Las phratriae, por otra parte, eran aquellas comunidades más amplias pero aún comprendidas dentro de los lazos de parentesco hermanados, como en el caso de los gene, bajo un ancestro común. Ibid. pp. 182-184.

98 "Only the power of the aristocratic gene was broken, not the gentilian spirit of its institutions. The demos, in spite of its territorial basis, were a corporation of persons just like the older blood-relationships. The Athenian still had his citizenship, not through a legal act making his person a member of the polis, but by his membership in a demos". Ibid., p. 184.

99 Homero, Odisea, en Obras Completas de Homero, versión directa y literal del griego por Luis Segalá y Estalella, Montaner y Simón, Barcelona, 1927, canto 9, 38-39, p. 362.

100 Homero, Ilíada, trad. de Luis Segalá y Estalella, Colección Austral, Madrid, 1954, canto XV, 486, p. 298.

101 "A Aquileo le vino el deseo de llorar por su padre, y, asiendo la mano de Príamo, la apartó suavemente. Entregados uno y otro a los recuerdos, Príamo, caído a los pies de Aquileo, lloraba copiosamente por Héctor, matador de hombres; y Aquileo lloraba unas veces a su padre [pues sabía que estaba anciano y que él mismo no sobreviviría la guerra ni reinaría en Ftía] y otras por Patroclo; y el gemir de ambos se alzaba en la tienda". Ibid., canto XXIV, p. 453. 
del espíritu y menos aún desembocan en el suelo básico de la experiencia ${ }^{102}$. Los suelos con sangre, también se volvería a apreciar con terrorífico esplendor en épocas muy cercanas a la nuestra, llevan más bien a anihilar el alma y a rebajar la existencia humana muy por debajo del confín de la política.

\section{Referencias bibliográficas}

Anderson, Bernhard W., "Politics and the Transcendent. Eric Voegelin's Philosophical and Theological Analysis of the Old Testament in the Context of the Ancient Near East": The Political Science Reviewer, n. ${ }^{\circ} 1$ (1971), pp. 1-29.

Alonso Rocafort, Víctor, Retórica, democracia y crisis. Un estudio de teoría política, Centro de Estudios Políticos y Constitucionales, Madrid, 2010.

Aristóteles, Política, trad., prólogo y notas de Carlos García Gual y Aurelio Jiménez Pérez, Alianza, Madrid, 1993.

Arendt, Hannah, "Comprensión y política", en De la historia a la acción, trad. de Fina Birulés, Paidós, I.C.E. de la U.A.B., Barcelona, 1999.

-, "El concepto de historia: antiguo y moderno", en Entre el pasado y el futuro. Ocho ejercicios para la reflexión política, trad. de Ana Poljak, Península, Barcelona, 2003.

—, “QQué es la autoridad?”, en Entre el pasado y el futuro. Ocho ejercicios para la reflexión política, trad. de Ana Poljak, Península, Barcelona, 2003.

-, "Discusión con amigos y colegas en Toronto", en Lo que quiero es comprender. Sobre mi vida y mi obra, trad. de Manuel Abella y José Luis López de Lizaga, Trotta, Madrid, 2010.

Bacon, Francis, The Great Instauration, 1620. Disponible en: http://www.constitution.org/ bacon/instauration.htm (15-8-2015).

Baird, Marie L., "Eric Voegelin's Vision of Personalism and Emmanuel Levinas's Ethics of Responsibility: Toward a Post-Holocaust Spiritual Theology?": The Journal of Religion, vol. 79, n. 3 (July, 1999), pp. 385-403.

Sagrada Biblia, versión crítica sobre los textos hebreo y griego, notas y comentarios de José María Bover y Francisco Cantera Burgos, Biblioteca de Autores Cristianos, Madrid, 1957.

Buber, Martin, Cuentos Jasídicos, Paidós, Buenos Aires, 1978.

-, The Legend of the Baal-Shem, trad. de Maurice Friedman, Princeton University Press, Princeton, 1995.

Della Porta, Donatella y Keating, Michael, "How Many Approaches in the Social Sciences? An Epistemological Introduction”, en Donatella Della Porta y Michael Keating (eds.), Approaches and Methodologies in the Social Sciences: a Pluralist Perspective, Cambridge University Press, Cambridge, 2008.

Draenos, Stan Spyros, “Thinking Without a Ground: Hannah Arendt and the Contemporary Situation of Understanding", en Melvin Hill (ed.), Hannah Arendt: The Recovery of the Public World, St. Martin Press, New York, 1979.

102 Hacia el final, cerca ya del combate que acaba con la vida de Héctor, Apolo, el protector de Héctor, identificado con la causa troyana, increpa a Aquileo: “¿Por qué, oh hijo de Peleo, persigues en veloz carrera, siendo tú mortal, a un dios inmortal? Aún no conociste que soy una deidad, y no cesa tu deseo de alcanzarme". Ibid., canto XXII, 8, p. 403. Aparece, así, el deseo de venganza y gloria. A Aquileo le mueve tanto su destino heroico como el dolor por la muerte de su amado Patroclo. Y no sería exagerado interpretar este fragmento de la trama más como una persecución o revuelta contra la experiencia de la trascendencia que como una unión o sintonía con ella. 
Dorado Romero, Juan, Fantasías de omnipotencia en la ciencia y la politica, tesis doctoral inédita, Departamento de Ciencia Política y de la Administración II, Universidad Complutense de Madrid, noviembre de 2015.

Easton, David, "The Decline of Modern Political Theory": The Journal of Politics, vol. 13, n. ${ }^{\circ} 1$ (1951), pp. 36-58.

Esquirol, Josep Maria, La resistencia intima. Ensayo de una filosofía de la proximidad, Acantilado, Barcelona, 2015.

Fructuoso, Josa, "La escritura interminable: Edmond Jabès: un extranjero con un libro bajo el brazo", en José Antonio Fernández López (ed.), Judaísmo finito, judaísmo infinito, ediciones Tres Fronteras, Murcia, 2009.

Forster, Ricardo, El exilio de la palabra. Ensayos en torno a lo judí, Libros ARCIS-LOM, Santiago de Chile, 1997.

Fueyo Álvarez, Jesús, "Eric Voegelin y su reconstrucción de la ciencia política": Revista de Estudios Políticos y Constitucionales, n. ${ }^{\circ} 79$ (1955), pp. 67-116.

Franzé, Javier, "Verdad y política: la crítica de Eric Voegelin a Max Weber sobre la relación entre ciencia y política": Astrolabio: Revista Internacional de Filosofía, n. 3 (2006), pp. 31-60.

Gillespie, Michael Allen, The Theological Origins of Modernity, University of Chicago Press, London, Chicago, 2008.

Grant, Ruth W., "Political Theory, Political Science and Politics": Political Theory, vol. 30, n. ${ }^{\circ} 4$ (August 2002), pp. 577-595.

Grinberg, León y Grinberg, Rebeca, Identidad y Cambio, Paidós, Barcelona, Buenos Aires, 1993.

Halbertal, Moshe y Margalit, Avishai, "Idolatry and Political Authority”, en Idolatry, trad. de Naomi Goldblum, Harvard University Press, Cambridge, 1992.

Harlow, Daniel C., "Idolatry and Alterity: Israel and the Nations in the Apocalypse of Abraham", en Daniel. C. Harlow, Matthew Goff, Karina Martin Hogan y Joel S. Kaminsky (eds.), The "Other" in the Second Temple Judaism. Essays in Honor of John Collins, Eerdmans, Grand Rapid, 2011.

Hogan, Maurice, "Editor's Introduction", en Eric Voegelin, Order and History: Israel and Revelation, vol. I, The Collected Works of Eric Voegelin, vol. 14, University of Missouri Press, Columbia, London, 2001.

Hegel, Georg W. F., "The Spirit of Christianity”, en On Christianity: Early Theological Writings, Harper Torchbooks, New York, 1961.

Hoces de la Guardia y Bermejo, Ángel L., "La hospitalidad en Homero": Gerión: Revista de Historia Antigua, vol. 5 (1987), pp. 43-56.

Homero, Odisea, en Obras Completas de Homero, versión directa y literal del griego por Luis Segalá y Estalella, Montaner y Simón, Barcelona, 1927.

—, Ilíada, trad. de Luis Segalá y Estalella, Colección Austral, Madrid, 1954.

Jonas, Hans, The Gnostic Religion. The Message of the Alien God and the Beginnings of Christianity, $3^{\mathrm{a}}$ ed., Beacon Press, Boston, 2001.

—, "Epilogue: Gnosticism, Existentialism, and Nihilism”, en The Gnostic Religionhe Gnostic Religion. The Message of the Alien God and the Beginnings of Christianity, $3^{\mathrm{a}} \mathrm{ed}$., Beacon Press, Boston, 2001.

Koyré, Alexandre, From the Closed World to the Infinite Universe, Johns Hopkins University Press, 1957. Disponible en: http://sacred-texts.com/astro/cwiu/cwiu15.htm (1-3-2016).

King, Gary, Keohane, Robert O. y Verba, Sydney, Designing Social Inquiry, Expanded edition, Princeton University Press, Princeton, 1995. 
Marinetti, Filippo Tomasso, "Le Futurisme”: Le Figaro (20-2-1909). [Versión en español: "El futurismo", trad. de Ramón Gómez de la Serna: Prometeo, n. ${ }^{\circ} 2$ (abril 1909). Disponible en: https://www.uclm.es/artesonoro/FtMARINETI/html/manifiesto.html (20-8-2015)].

Moulakis, Athanasios, "Editor's Introduction", en Eric Voegelin, Order and History: The World of the Polis, vol. II, The Collected Works of Eric Voegelin, vol. 15, ed. de Athanasios Moulakis, University of Missouri Press, Columbia, London, 2000.

Platón, Las leyes, trad. y notas de José Manuel Pabón y Manuel Fernández-Galiano, Alianza, Madrid, 2002.

—, República, trad. de Manuel Fernández-Galiano y José Manuel Pabón, Alianza, Madrid, 2006.

Roiz, Javier, "La teoría política de Eric Voegelin": Revista de Estudios Políticos (Nueva Época), n. ${ }^{\circ} 107$ (enero-marzo, 2000), pp. 33-75.

—, "Eric Voegelin: Existencia e inmortalidad", en La recuperación del buen juicio. Teoría política en el siglo veinte, Editorial Foro Interno, Madrid, 2003.

-, Sociedad vigilante y mundo judío en la concepción del estado, Editorial Complutense en colaboración con editorial Foro Interno, Madrid, 2008.

—, El mundo interno y la política, Plaza y Valdés, Madrid, 2014.

Schütz, Alfred, "Formación de conceptos y teorías en las ciencias sociales", en Maurice Natanson, El problema de la realidad social, Amorrortu, Buenos Aires, 1974.

Selltiz, Claire et al. (eds.), Research Methods in Social Relations, Holt Rinehart \& Winston, New York, 1963.

Strauss, Leo, "How to Begin to Study The Guide of the Perplexed", en Moses Maimonides, The Guide of the Perplexed, vol. I, The University of Chicago Press, Chicago, 1974.

Sófocles, Edipo rey, Pehuén editores, Santiago de Chile, 2001. Disponible en: http://www. pehuen.cl/files/pdf/EDIPOREY.PDF

Taubes, Jacob, "Martin Buber y sus filosofía de la Historia", en Del culto a la cultura. Elementos para una crítica de la razón histórica, Katz Editores, Buenos Aires, 2007.

Vallespín Oña, Fernando, "La vuelta a la tradición clásica: Leo Strauss, Eric Voegelin", en Fernado Vallespín Oña (ed.), Historia de la teoría política, vol. 5, Alianza, Madrid, pp. 342-382.

Vico, Giambattista, “Oración I”, en Obras.Oraciones inaugurales \& La antiquísima sabiduría de los italianos, trad. y notas de Francisco J. Navarro, Editorial Anthropos, Barcelona, 2002. .

Voegelin, Eric y Strauss, Leo, Fe y filosofía. Correspondencia 1934-1964, ed. y trad. de Antonio Lastra y Bernat Torres Morales, Trotta, Madrid, 2009.

Voegelin, Eric, Anamnesis, trad. y ed. de Gerhart Niemeyer, University of Missouri Press, Columbia, London, 1978.

- "Anxiety and Reason", en What is History? and Other Late Unpublished Writings. The Collected Works of Eric Voegelin, vol. 28, ed. de Thomas A. Hollbeck y Paul Caringella, Lousiana State University Press, Baton Rouge, London, 1990.

—, "Immortality: Experience and Symbol", en Published Essays 1966-1985, The Collected Works of Eric Voegelin, vol. 12, ed. de Ellis Sandoz, Louisiana State University Press, Baton Rouge, 1990.

-, Order and History: The World of the Polis, vol. II, The Collected Works of Eric Voegelin, vol. 15, ed. de Athanasios Moulakis, University of Missouri Press, Columbia, London, 2000.

-, Order and History: Israel and Revelation, vol. I, The Collected Works of Eric Voegelin, vol. 14, ed. de Maurice P. Hogan, University of Missouri Press, Columbia, London, 2001. 
—, "Science, Politics and Gnosticism: Two Essays", en Modernity without Restraint, The Collected Works of Eric Voegelin, vol. 5, ed. de Manfred Henningsen, University of Missouri Press, Columbia, 2000.

- La nueva ciencia de la política. Una introducción, trad. de Joaquín Ibarburu, Katz editores, Buenos Aires, 2006.

—, "Representación y Verdad", en La nueva ciencia de la política. Una introducción, trad. de Joaquín Ibarburu, Katz editores, Buenos Aires, 2006.

Walzer, Michael, Exodus and Revolution, Basic Books, New York, 1985.

Wolin, Sheldon S., "La era de la organización y la sublimación de la actividad política", en Política y Perspectiva. Continuidad y cambio en el pensamiento político occidental, Amorrortu editores, Buenos Aires, 2001.

—, "Political Theory as a Vocation": American Political Science Review, vol. 63, n. 4. [Versión en español: "La teoría política como vocación”: Foro Interno. Anuario de Teoría Política, vol. 11 (2011), pp. 193-234]. 